\title{
Experimental framework for evaluating the mechanical behavior of dry and wet crushable granular materials based on the particle breakage ratio
}

\author{
Carlos Ovalle, Christophe Dano, Pierre-Yves Hicher, and Mónica Cisternas
}

\begin{abstract}
It has been widely shown that particle crushing increases the compressibility of granular materials. For a particular crushable material and given test conditions, an empirical relation can be established between the breakage ratio and the plastic work. Along these lines, constitutive models have been developed based on the effect of grading evolution during crushing. In parallel, due to corrosive attacks of the humid environment at the tip of microcracks within solid grains, the mechanical behavior of crushable granular materials depends also on the water content: the higher the material humidity, the higher the particle crushing. However, the experimental data on the relation between loading-wetting conditions and the breakage ratio are still quite scarce. In this paper, we present experimental results on crushable sand to study the effect of flooding under isotropic, oedometric, and triaxial stress paths. The main objective of this study is to obtain a consistent framework for the effect of water based on the breakage ratio. Our results have shown that, for a given initial density and stress path, the dry material after flooding reaches the equivalent behavior of the initially wetted material in terms of compression curve, particle crushing, and creep compressibility index, regardless of the point of flooding. Moreover, the relation between the breakage ratio and the final void ratio is unique and depends neither on the stress path, the water content, the point of flooding, nor the loading condition (time of creep or relaxation), but exclusively on the initial density and on intrinsic parameters. These findings could improve the prediction of the effect of water and time on the mechanical response of crushable granular materials through constitutive models based on grading evolution.
\end{abstract}

Key words: crushable granular materials, compressibility, grain-size distribution, creep, stress relaxation.

Résumé : Il est reconnu que la rupture des grains augmente la compressibilité des matériaux granulaires. Pour des conditions d'essai données, une relation empirique peut être établie entre le taux de rupture des grains et le travail plastique. Ainsi, des modèles constitutifs ont été développés sur la base de l'évolution de la granulométrie liée à cette rupture des grains. Parallèlement, du fait des attaques corrosives de l'environnement humide en pointe des micro-fissures dans les grains solides, le comportement mécanique des matériaux granulaires broyables dépend également de la teneur en eau: plus l'humidité du matériau est élevée, plus la rupture semble favorisée. Toutefois, les données expérimentales sur la relation entre les conditions de chargement, les conditions hydriques et le taux de rupture sont encore très rares. Dans cet article, on présente des résultats expérimentaux sur un sable affecté par la rupture des grains pour étudier l'effet de l'imbibition sur des chemins de contraintes isotropes, œdométriques, et triaxiales. L'objectif principal de cette étude est d'obtenir un schéma de comportement cohérent décrivant l'effet de l'eau sur le taux de rupture des grains. Les résultats montrent que, pour une densité initiale et un chemin de contraintes donné, après l'imbibition d'un échantillon sec, il suit un comportement identique à celui d'un échantillon saturé dès le début du chargement en termes de compressibilité, ruptures des grains et d'indice de compressibilité au fluage, quel que soit le point d'imbibition. Par ailleurs, la relation entre le taux de rupture et l'indice des vides final est unique et ne dépend pas du chemin de contraintes, ni de la teneur en eau, ni du point initial de l'imbibition, ni des conditions de chargement (temps de fluage ou de relaxation), mais uniquement de la densité initiale et de paramètres intrinsèques. Ces résultats pourraient améliorer la prédiction de l'effet de l'eau et du temps sur la réponse mécanique des matériaux granulaires broyables à l'aide des modèles constitutifs basés sur la granulométrie.

Mots-clés : matériaux granulaires broyables, compressibilité, granulométrie, fluage, relaxation des contraintes.

\section{Introduction}

Granular materials are present in many civil engineering problems, such as foundations on sands or gravels, railway ballasts and rockfills embankments. It is well known that their mechanical behavior is a function of the properties of the granular packing and its water content, as well as of the mechanical and geometrical characteristics of individual grains. Under given conditions, intergranular contact forces can exceed particle strength and a fraction of the particles will crush, changing the grain-size distribution (GSD) towards a more polydisperse packing, which creates a denser arrangement for a given stress condition (Biarez and Hicher 1997; Li et al. 2013). After crushing, consequently compressibility will increase and dilatancy under shear become reduced, as well as the peak shear strength (Vesic and Clough 1968; Marachi 
et al. 1972; Marsal 1973; Coop and Lee 1995; Lee and Coop 1995; Lade et al. 1996; Ovalle et al. 2013b). In general, grain crushing occurs under high stresses, e.g., at pile tips or at the base of high dams, or under quite lower stresses in materials composed of relatively weak grains. The amount of grain crushing is normally analyzed in terms of the breakage ratio $B_{\mathrm{r}}$ (Marsal 1973; Hardin 1985; Lade et al. 1996; Einav 2007a). In this work, we use a recent $B_{\mathrm{r}}$ definition proposed by Einav (2007a), obtained as the ratio between (i) the area flanked by the initial GSD and any intermediate GSD after crushing $\left(B_{\mathrm{t}}\right.$ in Fig. 1$)$ and (ii) the initial GSD and an assumed ultimate fractal GSD $\left(B_{\mathrm{p}}\right.$ in Fig. 1, assuming a fractal dimension $D=2.5$ for a cumulated GSD given by $G(d)=\left(d / d_{\max }\right)^{3-D}$, where $d$ is the grain diameter and $d_{\max }$ is the maximum grain diameter).

The experiments by Miura and O-Hara (1979), Hu et al. (2011), and Ovalle et al. (2013a) have shown that the amount of grain crushing is related to the total amount of plastic work. These findings have led to developing phenomenological constitutive models based on the general framework of uncrushable soils (i.e., the critical state theory). Accordingly, extra plastic strain after crushing is given by an inverse relation between the critical void ratio and the breakage ratio (Daouadji et al. 2001; Russell and Khalili 2004; Muir Wood et al. 2009; Daouadji and Hicher 2010; Hu et al. 2011). The alternative method proposed by McDowell and Bolton (1998) linking the plastic work to the increment of the surface fracture energy on crushed grains has been confronted with experiments by Russell (2011) and Ovalle et al. (2013a). On the other hand, Einav $(2007 a, 2007 b)$ used the breakage ratio as an internal energy parameter, which opened the way to the prediction of grading and its link to the mechanical response.

In fact, the source of grain crushing comes from the breakage mechanics of individual grains at the micromechanical scale. In other words, it depends on the mechanical properties of grains and their loading conditions at intergranular contacts. Therefore, multi-scale links are conducive to predict the response of the granular assembly. Recently, the multi-scale approaches developed take into account physical parameters such as the tensile particle strength, grain-size effects, and the fracture surface energy of brittle solid grains (McDowell and Bolton 1998; Frossard et al. 2012; Ovalle 2013; Ovalle et al. 2013c). A close look at the microscopic scale (i.e., microcracks or flaws inside individual particles) gives a physical explanation of this phenomenon, as described by classical brittle fracture mechanics. Griffith (1921) proposed that fracture in perfectly linear elastic brittle materials occurs through the propagation of existing cracks. He demonstrated that the induced tensile stress $(\sigma)$ depends only on the size of the crack $(a)$ and on intrinsic parameters. Later, Irwin (1957) developed the notion of stress intensity factor under uniform axial stress $\left(K_{\mathrm{I}}=\sigma \mathrm{V}(\pi a)\right)$ and fracture toughness ( $K_{\mathrm{IC}}$ for fracture in mode I). The term $K_{\mathrm{IC}}$ can be defined as the material resistance to fracture by crack propagation. Hence, a crack begins to grow when $K_{\mathrm{I}}$ reaches the limit $K_{\mathrm{IC}}$.

Exposed to rain or dam leakage, for instance, granular soils undergo significant changes in water content, from an almost dry state to complete saturation. For crushable materials, an increase in relative humidity will cause more particle crushing for a given stress condition (Marsal 1973; Lee and Coop 1995; Oldecop and Alonso 2003; Ovalle et al. 2013a). Consequently, the mechanical behavior of the granular material is affected as explained before. At the micromechanical scale, variations in the material water content will affect the $K_{\text {IC }}$ (Oldecop and Alonso 2007). This issue has been discussed by many authors who found that the value of $K_{\text {IC }}$ depends on the degree of saturation and on the physicochemical composition of both solid material and liquid. Westwood (1974), Atkinson $(1979,1982)$, and Dunning et al. (1984), for example, consider that the problem is quite complex because the degradation of the structural integrity of geological materials is mainly due to the corrosive attacks of the environment. The ef-
Fig. 1. Definition of the breakage ratio $B_{\mathrm{r}}$ (modified from Einav $2007 a$, with permission from Elsevier).

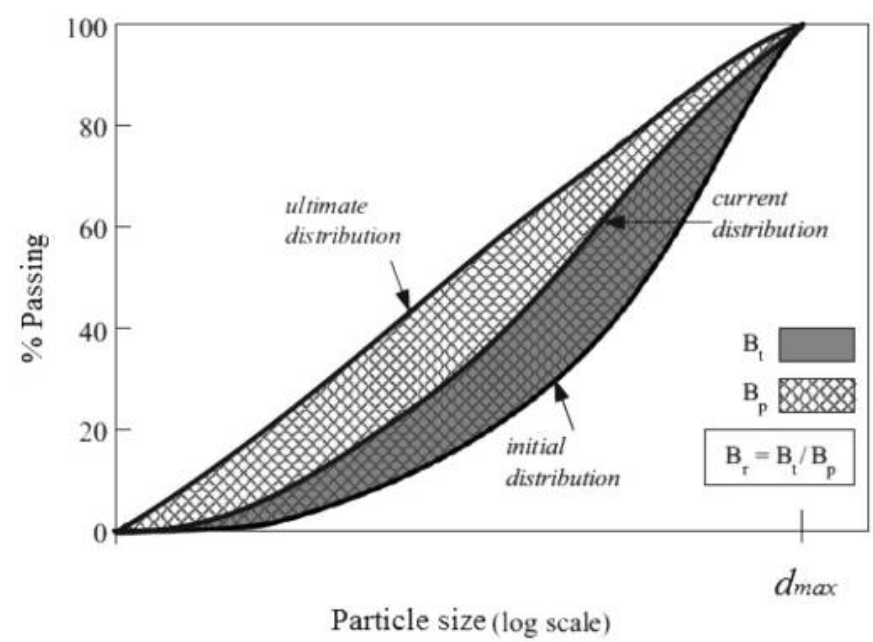

fects are essentially the adsorption of elements and mineral dilution from the environment around the microcrack tip, which causes a modification of the fracture surface energy, and the electrostatic interaction between the humid environment and the material. Moreover, if the material water content increases, the capillary suction will decrease at the microcrack tips within the grains. Therefore, the effective stress against crack opening also decreases and the mechanism is affected: crack propagation velocity increases and both particle strength and $K_{\mathrm{IC}}$ decrease (Oldecop and Alonso 2007). Therefore, the higher the water content in the material voids, the lower the $K_{\mathrm{IC}}$ value and the higher the particle crushing. However, rather than the material pore water into the entire assembly, what is relevant is how much water is retained inside rock microcracks forming the grains.

A number of models for crushable granular materials including the effect of the water content have been suggested. For instance, by using the results of compression tests on rockfills under relative humidity control, Oldecop and Alonso $(2001,2003)$ and Chávez and Alonso (2003) developed a phenomenological constitutive model based on work hardening plasticity and critical state theory, which incorporated the effect of suction. Considering the loading collapse curve concept from unsaturated soil mechanics, their model gives numerical results based on the role of suction that is related to the relative humidity in the material voids. Similarly, Oldecop and Alonso (2007) suggested a conceptual model to explain the creep behavior in rockfills based on the influence of suction on $K_{\mathrm{IC}}$ and on an inverse relation between $K_{\mathrm{IC}}$ and the crack propagation velocity. On the other hand, Buscarnera and Einav (2012) proposed a model based on the thermo-mechanical approach proposed by Einav (2007a, 2007b), where the loading collapse curve is linked to the energy balance. The model links the assumption of energy dissipation by particle breakage and the capillary theory for solid-fluid interaction. Finally, Bauer (2009) developed a hypoplastic model based on a solid hardness concept where the mechanical response is simply enclosed between a compression curve for the dry condition and a more compressible one for the saturated material.

Despite the many advances made in understanding the phenomenon of grain crushing, the role of the breakage ratio as a governing parameter for the effect of the water content on crushable soils is still not very clear. Experimental data on the subject are generally not available. We, therefore, carried out an extensive experimental program of the effects of flooding in crushable granular material by running a series of tests including different stress paths, stress magnitudes, with stages of stress relaxation and creep, and by checking test repeatability to obtain a consis- 
tent framework based on grading evolution. The main objectives are to study the influence of stress path, water content and time, as well as the link between the mechanical behavior and the evolution of the breakage ratio. Then, based on experimental evidences, we suggest an integrated analysis of the material behavior with the perspective of enhancing constitutive models based on grading, including the effects of water content and time.

\section{Tested material}

The granular material tested is an angular sand obtained from the grinding of a quartzite shale rock from the Trois Vallées quarry, in the north of France. Samples were prepared with an initial uniform GSD sieved between 2 and $2.5 \mathrm{~mm}$. Figure 2 presents a photo of the material before the test. It can be seen that the particles are mainly angular and flat, which makes them vulnerable to crushing. Solid grains have a volumetric weight of $27 \mathrm{kN} / \mathrm{m}^{3}$. Figure 3 presents electron microscope scans of fine fractions of crushed grain fragments sieved after a test. For finer grains in Fig. $3 a$, it clearly appears that the shale rock is composed of thin sheets. Once crushing occurs, a significant amount of fines is produced essentially by small pieces of detached sheets. The analysis of X-ray diffraction (XRD) of a fine fraction of the material (grain sizes finer than $0.08 \mathrm{~mm}$ ) shows that the powder is composed mainly of oxygen and silicon, with also significant amounts of aluminum and iron. The XRD measurement results show the presence of three main phases: $64 \%$ of quartz $\left(\mathrm{SiO}_{2}\right), 26 \%$ of albite $\left(\mathrm{NaAlSi}_{3} \mathrm{O}_{8}\right)$, and $10 \%$ of sodium aluminium silicate $\left(\mathrm{Na}_{6} \mathrm{Al}_{6} \mathrm{Si}_{10} \mathrm{O}_{32}\right)$.

To avoid crushing during the preparation, loose samples of dry material were prepared in cylindrical moulds by pluviation at low height. The material was previously air dried for at least 1 week in a constant clime chamber at $20{ }^{\circ} \mathrm{C}$ and $60 \%$ of relative humidity, where all tests were finally carried out. Here, we consider the material as dry after air drying, even if a water content of $0.5 \%$ was measured (obtained by weight changes after $24 \mathrm{~h}$ of oven drying at $105{ }^{\circ} \mathrm{C}$ ). Under this condition, no capillary bonds were observed between particles and the apparent cohesion was negligible. As explained below, some samples were saturated or flooded with demineralized water after a phase of compression. Water was slowly added to dry samples through a pipe connected to its base, a constant water level being maintained slightly above the upper level of the sample. Due to the low water content of the specimen after drying, we simply used the notation of "dry" and "saturated" for the two opposite initial states of the specimens prior to loading. However, such observation applies to the entire sand sample, rather than into microcrack within the grains. After saturation or flooding, no chemical reaction or mineral dilution of wetted sand grains was observed. After each test, the samples were dried for $24 \mathrm{~h}$ in a $105{ }^{\circ} \mathrm{C}$ oven and then accurately sieved between 2.5 and $0.08 \mathrm{~mm}$.

\section{Experimental results}

\section{Triaxial and isotropic compression tests}

Loose samples of dry material were prepared at an average void ratio (volume of voids/volume of solids) of $0.937 \pm 0.035$ in a cylindrical mould $110 \mathrm{~mm}$ high and $70 \mathrm{~mm}$ in diameter, using a $1 \mathrm{~mm}$ thick latex membrane. See tests D1 to F8 in Table 1, where code D stands for dry, $\mathrm{S}$ for saturated, and F for flooded. Strain controlled isotropically consolidated drained triaxial compression tests at effective confining pressures $\left(\sigma_{3}^{\prime}\right)$ of 0.4 and $0.8 \mathrm{MPa}$ were performed using a vertical displacement rate of $0.2 \mathrm{~mm} / \mathrm{min}$ (i.e., a vertical strain rate of about $2 \% / \mathrm{min}$ ). Since we considered dry and saturated cases (i.e., referring to macropores between grains) and drained tests on rather coarse uniform sand, no suction or excess pore pressure were measured during testing and the definition of the effective stress used here coincides with the classical Terzaghi's principle. The volume changes of the samples were measured through the confinement water volume control system.
Fig. 2. 2 to $2.5 \mathrm{~mm}$ grains of shale quartzite sand from Trois Vallées.

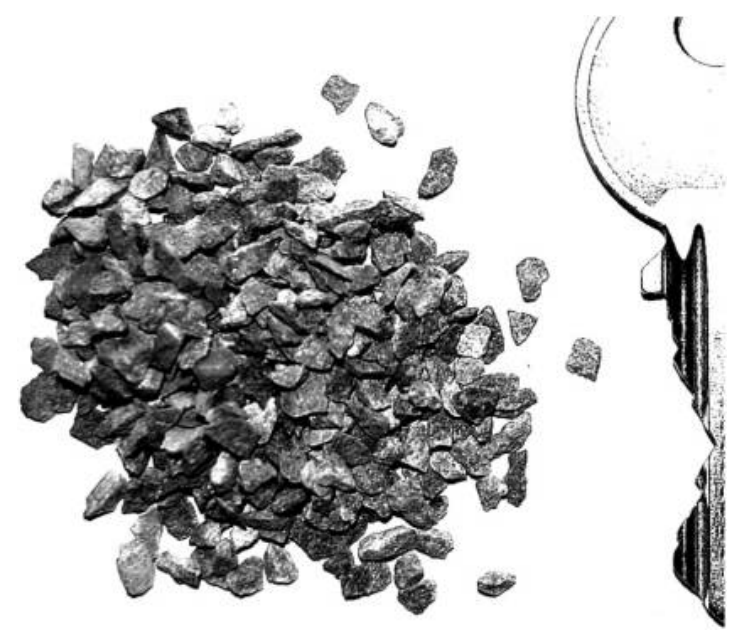

Thus, the triaxial cell deformation under isotropic water pressure was firstly calibrated without the sand sample to isolate the volumetric strain of the cell from the sample one.

Some tests were flooded after the isotropic consolidation phase and others after a triaxial compression up to $7 \%$ to $12 \%$ of axial strain $\left(\varepsilon_{\mathrm{a}}\right)$ (see tests F4, F5, F6, and F8 in Table 1). First, the vertical strain was stopped at a given level and then flooding was carried out by imposing a water flow through the sample from the bottom to the top face by using a volume pressure controlled system. Back pressure was carefully maintained lower than the water level between the device and the top of the sample to avoid any change in the confining pressure. Once water started to appear on the top pipe connection of the sample, the water flow was stopped. This process took approximately $5 \mathrm{~min}$. Then, a period of deviatoric stress $\left(q=\sigma_{1}-\sigma_{3}\right)$ relaxation of 1-2 $\mathrm{h}$ was applied (i.e., at both constant $\varepsilon_{\mathrm{a}}$ and $\sigma_{3}^{\prime}$ ), before a further increase of the axial strain was imposed. The final $\varepsilon_{\mathrm{a}}$ for all triaxial tests was $20 \%$. Figure 4 shows the time evolution of the void ratio, $e$, and of the deviatoric stress, $q$, during the tests. It can be seen in tests F4, F6, and F8 that the relaxation phase leads to a significant drop of $q$. Similarly, there is also a slight decrease in the void ratio during the relaxation phase, due to creep at constant $\sigma_{3}^{\prime}$.

To study separately the deviatoric stress relaxation in the dry material and the effect of flooding, two stages of relaxation were applied in test F5. Firstly, the test was conducted up to $\varepsilon_{a}=10 \%$ and then stopped for $1.5 \mathrm{~h}$ of stress relaxation. Then, the sample was flooded and an extra hour of relaxation was applied. Figure 5 shows the evolution in time of the void ratio and of the deviatoric stress for test F5. It can be seen that the relaxation of the dry material is in the order of $\Delta q=-0.23 \mathrm{MPa}$ and, after the stabilization of $q$ in the dry condition, a further decrease of $q$ of about $0.4 \mathrm{MPa}$ occurred once the sample was flooded. That is to say, $1 / 3$ of $\Delta q$ corresponds to the behavior of the dry material and the rest is added after flooding, possibly because grain crushing was triggered in the presence of water.

Similarly, dry and flooded drained isotropic compression tests at $\sigma_{3}^{\prime}$ of 0.4 and $0.8 \mathrm{MPa}$ were carried out using the same sample preparation method as for the triaxial tests. The average void ratio was $0.980 \pm 0.088$ (see tests D9 to F13 in Table 1). Isotropic tests were performed under stress controlled conditions. For a given $\sigma_{3}^{\prime}$, the dry sample was firstly compressed and then allowed to creep for $1 \mathrm{~h}$ at constant stress (tests D9 and D10). In tests F11, F12, and F13, the samples were flooded and kept for an extra hour of creep.

Figure 6 shows the stress-strain response after the triaxial tests in terms of the stress ratio $q / p^{\prime}$ (where $p^{\prime}=\left(\sigma_{1}^{\prime}+2 \sigma_{3}^{\prime}\right) / 3$ ) and the void ratio, and Table 1 presents the breakage ratio. It can be seen that, regardless of the point of flooding, the material is more compress- 
Fig. 3. Crushed grains of quartzite shale sand after uniaxial compression test sieved between (a) 0.08 and $0.1 \mathrm{~mm}$, (b) 0.315 and $0.4 \mathrm{~mm}$, and (c) 0.5 and $0.6 \mathrm{~mm}$.
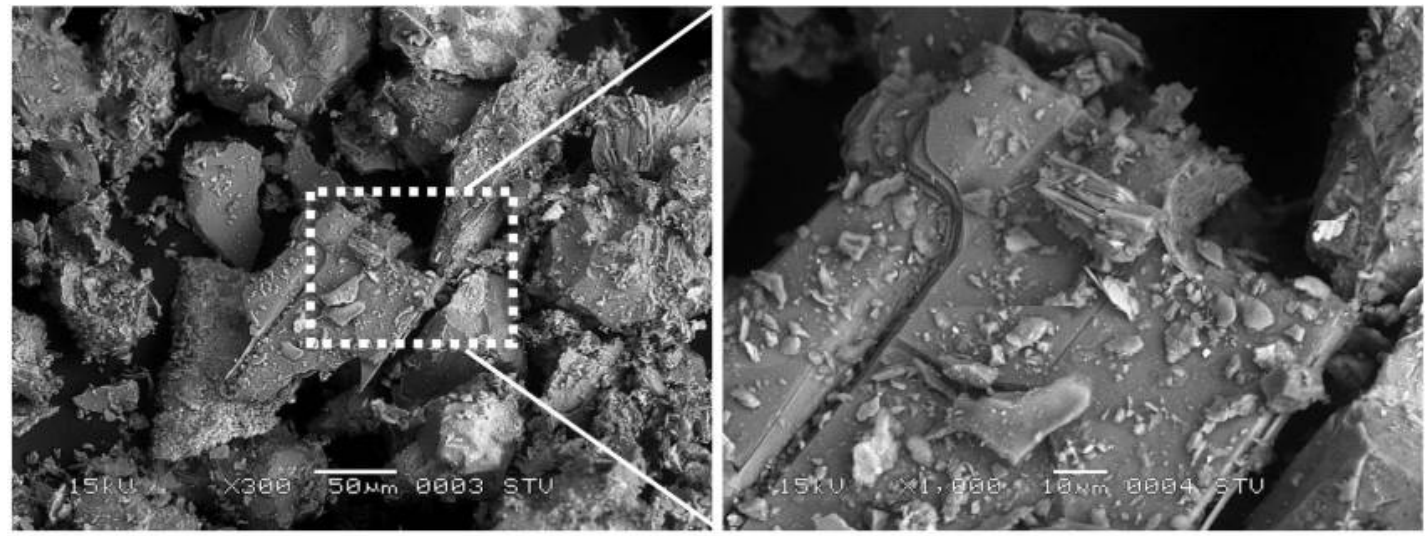

(a)

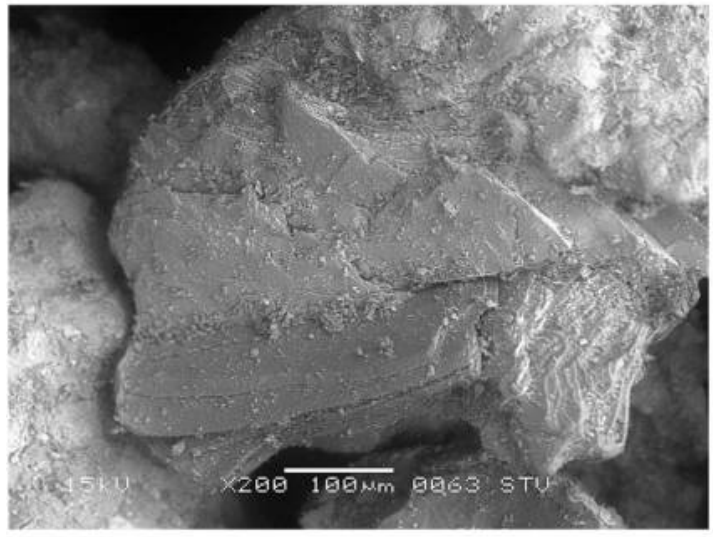

(b)

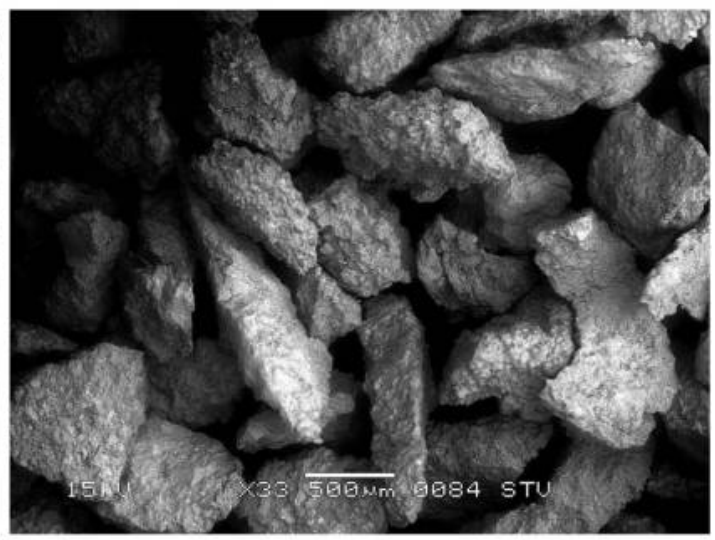

(c) ible after flooding. Moreover, all samples flooded at a given $\sigma_{3}^{\prime}$ in a triaxial test joined approximately the same volumetric response and almost the same $B_{\mathrm{r}}$ (i.e., the same final GSD). For instance, see $B_{\mathrm{r}}$ and the $e-p^{\prime}$ plane for tests F3 to F6 in Table 1 and Fig. 6, respectively.

\section{Oedometer tests}

Loose samples of dry material were prepared at an average void ratio of $1.018 \pm 0.05$ in a cylindrical oedometric device of $19 \mathrm{~mm}$ high and $70 \mathrm{~mm}$ of diameter (see tests D14 to F25 in Table 1). Stress controlled oedometric compression tests were performed using the following effective vertical stress levels: $\sigma_{\mathrm{v}}^{\prime}=0.15,0.40,0.60$, $0.85,1.15,1.50$, and $2.10 \mathrm{MPa}$. To reach a given stress level, each aforementioned stress value was allowed $1 \mathrm{~h}$ of strain stabilization. Thus, even if the full stabilization was not attained after $1 \mathrm{~h}$, this time of creep allowed comparing the results with the previous triaxial and isotropic tests. To obtain the evolution of the GSD during crushing, the samples were unloaded at various maximum effective stress $\left(\sigma_{\mathrm{v} \text { max }}^{\prime}\right)$, as shown in Table 1 . The tests were performed for three sample conditions: dry, saturated, and flooded. In this case, a saturated material stands for a sample that was initially flooded, i.e., before the initial loading stage of $\sigma_{\mathrm{v}}^{\prime}=$ $0.15 \mathrm{MPa}$.

Figure 7 presents the oedometric compression curves, where it can be seen that a good repeatability was obtained. Hence, two main compression curves can be identified, one for the dry condition and the other for the saturated and flooded conditions. For example, tests F22, F23, F24, and F25 were flooded at $\sigma_{\mathrm{v}}^{\prime}$ of 0.40 ,
$0.40,0.85$, and 1.5 MPa, respectively. It can be seen that these tests followed the dry compression curve before flooding, and after the addition of water they behaved in the same way as the saturated material. Then, after flooding and $1 \mathrm{~h}$ of creep in tests F22 and F25, $\sigma_{\mathrm{v}}^{\prime}$ was increased up to $2.10 \mathrm{MPa}$ and the compression curve followed the saturated material response. Consequently, regardless of the point of flooding, the oedometric compression curve is unique for saturated and flooded samples. This result agrees with the experimental evidence from the literature (Oldecop and Alonso 2003) and also with our own triaxial tests results. Figure 8 presents the GSD only for oedometer tests at $\sigma_{\mathrm{v} \text { max }}^{\prime}=2.1 \mathrm{MPa}$. These results clearly show that after flooding in test F25, the material reaches almost the same GSD as the one of the saturated sample (test S21), with more grain crushing compared to the dry case (test D18).

\section{Creep in oedometer tests}

To study the creep behavior of the material, a second series of oedometer tests was carried out. Using the same aforementioned method, several loose samples at a void ratio of $1.019 \pm 0.046$ were prepared. Table 2 shows a summary of the test conditions on loose samples (test D26 to F48). The following effective vertical stress levels were imposed: $\sigma_{\mathrm{v}}^{\prime}=0.15,0.4,0.8,1.3$, and $2.1 \mathrm{MPa}$. This time, the load was kept for $24 \mathrm{~h}$ at each level. Thus, to reach a given $\sigma_{\mathrm{v} \text { max }}^{\prime}$ in a test, a time of $24 \mathrm{~h}$ of creep was allowed at each mentioned stress level and for each test condition. Therefore, at least three tests for each stress level were carried out on dry, saturated, 
Table 1. Summary of triaxial, isotropic, and oedometric compression tests.

\begin{tabular}{|c|c|c|c|c|c|c|}
\hline Test & $\begin{array}{l}\text { Test } \\
\text { No. }\end{array}$ & $\begin{array}{l}\text { Initial } \\
\text { void ratio }\end{array}$ & $\begin{array}{l}\sigma_{\mathrm{y} \max }^{\prime} \text { or } \\
\sigma_{3}^{\prime}(\mathrm{MPa})^{*}\end{array}$ & $\begin{array}{l}B_{\mathrm{r}} \\
(\%)\end{array}$ & $\begin{array}{l}W^{\mathrm{p}} \\
(\mathrm{MPa})\end{array}$ & Test conditions \\
\hline \multirow[t]{8}{*}{ Triaxial } & D1 & 0.933 & 0.80 & 22 & 0.372 & Dry \\
\hline & F2 & 0.929 & 0.40 & 25 & 0.361 & Flooded after isotropic consolidation \\
\hline & F3 & 0.935 & 0.80 & 25 & 0.345 & Flooded after isotropic consolidation \\
\hline & F4 & 0.945 & 0.80 & 23 & 0.338 & Flooded at $\varepsilon_{\mathrm{a}}=12 \%$ \\
\hline & F5 & 0.903 & 0.80 & 24 & 0.335 & Flooded at $\varepsilon_{\mathrm{a}}=10 \%$ \\
\hline & F6 & 0.948 & 0.80 & 26 & 0.359 & Flooded at $\varepsilon_{\mathrm{a}}=8 \%$ \\
\hline & D7 & 0.949 & 0.40 & 17 & 0.199 & Dry \\
\hline & F8 & 0.957 & 0.40 & 18 & 0.195 & Flooded at $\varepsilon_{\mathrm{a}}=7 \%$ \\
\hline \multirow[t]{5}{*}{ Isotropic } & D9 & 1.069 & 0.40 & 4 & 0.010 & Dry \\
\hline & D10 & 0.955 & 0.80 & 6 & 0.019 & Dry \\
\hline & F11 & 0.991 & 0.40 & 4 & 0.009 & Flooded after $1 \mathrm{~h}$ of creep at $\sigma_{3}^{\prime}=0.4 \mathrm{MPa}$ \\
\hline & F12 & 0.952 & 0.80 & 8 & 0.018 & Flooded after $1 \mathrm{~h}$ of creep at $\sigma_{3}^{\prime}=0.8 \mathrm{MPa}$ \\
\hline & F13 & 0.967 & 0.80 & 7 & 0.025 & Flooded after $1 \mathrm{~h}$ of creep at $\sigma_{3}^{\prime}=0.8 \mathrm{MPa}$ \\
\hline \multirow{12}{*}{ Oedometric $^{\dagger}$} & D14 & 1.066 & 0.40 & 6 & 0.033 & Dry \\
\hline & D15 & 1.015 & 0.60 & 7 & 0.032 & Dry \\
\hline & D16 & 0.995 & 0.85 & 8 & 0.040 & Dry \\
\hline & D17 & 1.014 & 2.10 & 13 & 0.118 & Dry \\
\hline & D18 & 0.990 & 2.10 & 14 & 0.123 & Dry \\
\hline & S19 & 1.035 & 0.40 & 8 & 0.016 & Saturated (or initially flooded) \\
\hline & $\mathrm{S} 20$ & 1.029 & 0.85 & 12 & 0.046 & Saturated \\
\hline & S21 & 1.051 & 2.10 & 22 & 0.174 & Saturated \\
\hline & F22 & 1.008 & 2.10 & 21 & 0.173 & Flooded at $\sigma_{\mathrm{v}}^{\prime}=0.40 \mathrm{MPa}$ and reloaded to $2.1 \mathrm{MPa}$ \\
\hline & F23 & 1.009 & 0.40 & 8 & 0.018 & Flooded at $\sigma_{\mathrm{v}}^{\prime}=0.40 \mathrm{MPa}$ \\
\hline & F24 & 1.000 & 0.85 & 12 & 0.052 & Flooded at $\sigma_{\mathrm{y}}^{\prime}=0.85 \mathrm{MPa}$ \\
\hline & F25 & 1.003 & 2.10 & 21 & 0.201 & Flooded at $\sigma_{\mathrm{v}}^{\prime}=1.50 \mathrm{MPa}$ and reloaded to $2.1 \mathrm{MPa}$ \\
\hline
\end{tabular}

and flooded samples. Moreover, some tests were repeated to check the repeatability of the results.

Figure 9 shows the compression curves for tests D26 to F48. Thus, the same conclusions drawn for $1 \mathrm{~h}$ of creep in oedometric compression can be obtained in this case. Namely, the existence of two separated compression curves, one for the dry material and the other for both saturated and flooded samples, resulting in a more compressible behavior in the presence of water. Moreover, the same final GSD for saturated and flooded samples was attained for a given $\sigma_{\mathrm{v} \text { max }}^{\prime}$, as shown in Fig. 10 for $\sigma_{\mathrm{v} \text { max }}^{\prime}=2.1 \mathrm{MPa}$. This finding is consistent with our results in triaxial and previous oedometer tests results and, as far as we know, has not been reported in the literature to this day.

Figure 11 presents the compression curves on effective stress log-scale for selected oedometric tests D18, S20, F22, and F25. It can be seen that a yielding point, normally associated to the onset of crushing, cannot be clearly identified. In fact, as shown in Fig. 12, breakage starts occurring even at the lowest stress value used here, which means that the material behaves in an inelastic regime almost from the beginning of the test.

Figure 13 presents the volumetric strain evolution for $24 \mathrm{~h}$ of creep for $(a)$ dry, $(b)$ saturated, and (c) flooded samples, for every stress increment. Figure $14 a$ presents the time dependent compressibility index defined as $\Delta \varepsilon_{\mathrm{v}} / \Delta[\log (t)]$ (where $t$ is time in minutes, measured from $1 \mathrm{~min}$ to $24 \mathrm{~h}$ ). As shown previously by Oldecop and Alonso (2007), it is clear that the dry samples have a lower index and the flooded ones joined the index of the saturated samples after flooding. This last statement can be clearly appreciated in Fig. $14 b$ for three representative tests at $\sigma_{\mathrm{v} \text { max }}^{\prime}=2.1 \mathrm{MPa}$.

\section{Effect of water on the fracture toughness of rock samples}

To study the water effect at the source of the particle crushing phenomenon (i.e., at the individual grain scale), we performed crushing tests on core rock samples. We used the cracked chevron notched Brazilian disc (CCNBD) method to obtain $K_{\mathrm{IC}}$, as suggested by the International Society for Rock Mechanics (Fowell
1995). This method gives consistent fracture toughness values and allows testing rock anisotropy since the crack orientations can be easily arranged. The geometry of the CCNBD samples is shown in Fig. 15, where the chevron or V-shaped notch was cut using a circular diamond saw. The notch cut along the core diameter causes crack propagation to start at the tip of the $\mathrm{V}$ alignment and to proceed radially outwards in a stable mode until the point where the fracture toughness is evaluated (Fowell 1995).

For the quartzite shale rock tested in this study, we machined rock cores of $D=52 \mathrm{~mm}$ in diameter from large rock aggregates. The cores had both parallel and orthogonal orientations with respect to the rock anisotropies composed by the sheeted structure of the shale rock (see Fig. 16). Rock samples with thickness of $B=$ $21.5 \mathrm{~mm}$ were cut from the cores. As shown in Fig. 15, the notch characteristic dimensions were $a_{\mathrm{o}}=6.53 \mathrm{~mm}, a_{1}=19 \mathrm{~mm}$, and $R_{\mathrm{s}}=$ $19.25 \mathrm{~mm}$. The fracture toughness tests were carried out using a loading frame of $50 \mathrm{kN}$ of maximum capacity, driven by controlled displacement at $0.1 \mathrm{~mm} / \mathrm{s}$. Figure 17 shows the setup of the sample for testing, with vertical displacement sensors and force measurements. The tests were performed in the same clime conditioned chamber used for the compression tests on granular material. We conducted tests on air-dried samples, as well as on samples submerged in water for $24 \mathrm{~h}$ before testing. The core samples were machined from two coarse rock aggregates (see aggregate No. 2 in Fig. 16). Due to the heterogeneity of the shale rock and to clearly identify the effect of water in $K_{\mathrm{IC}}$, we compare only the cores coming from the same aggregate.

Tables 3 and 4 present $K_{\mathrm{IC}}$ values measured for orthogonal and parallel core orientations, respectively. Our tests results are in the same order of magnitude as typical values of $K_{\mathrm{IC}}$ for shale rocks reported in the literature of approximately $0.5-1.0 \mathrm{MPa} \cdot \mathrm{m}^{0.5}$ (Whittaker et al. 1992; Ashby and Jones 2006). In particular, for dry orthogonal oriented cores coming from aggregate No. 1 we obtained $K_{\mathrm{IC}} \approx 1.5 \mathrm{MPa} \cdot \mathrm{m}^{0.5}$ and an average reduction of approximately $60 \%$ in saturated specimens with $K_{\mathrm{IC}} \approx 0.6 \mathrm{MPa} \cdot \mathrm{m}^{0.5}$. 
Fig. 4. Stress relaxation during flooding in tests (a) F4, (b) F6, and (c) F8.

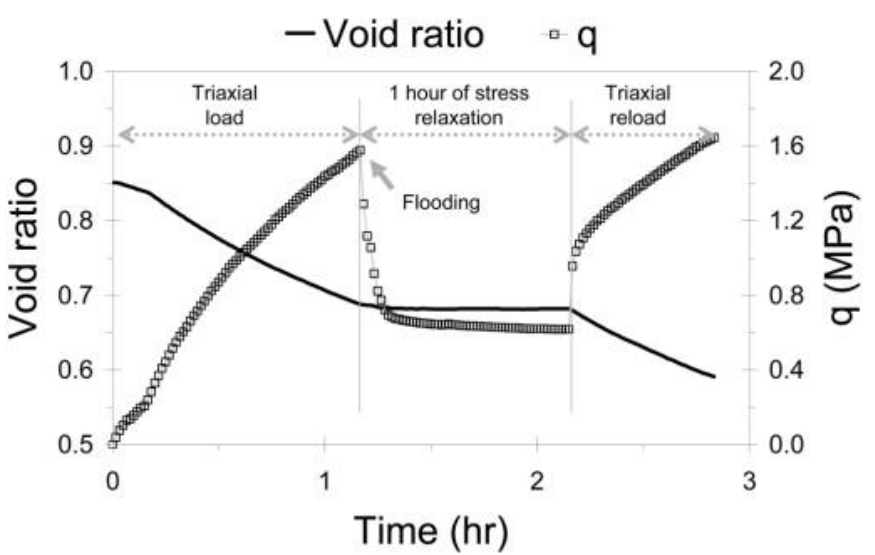

(a) Test F4

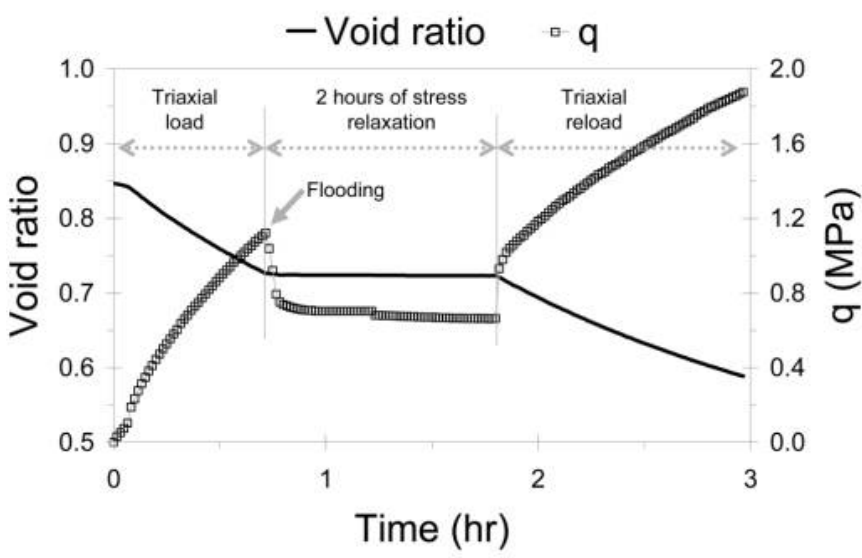

(b) Test F6

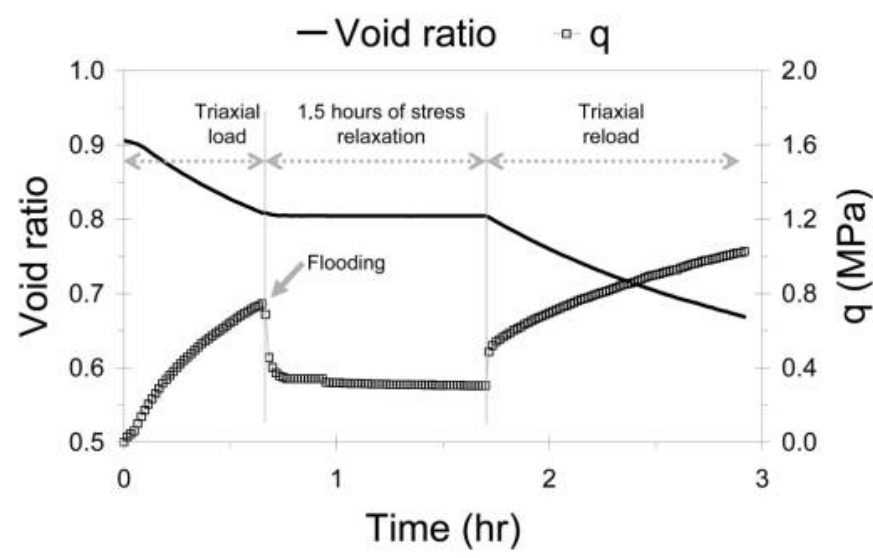

(c) Test F8

Similarly, for orthogonal oriented cores from aggregate No. 2, we measured a reduction in $K_{\mathrm{IC}}$ of approximately $20 \%$ to $30 \%(0.54-$ 0.63 to $0.42 \mathrm{MPa} \cdot \mathrm{m}^{0.5}$ ) from dry to saturated specimens. On the other hand, in parallel oriented samples $K_{\text {IC }}$ drops significantly compared to the previous case, due to the induced chevron notch being in the weakest plane of the rock. Moreover, the difference between dry and saturated specimens is less important and $K_{\mathrm{IC}}$ is almost the same in aggregate No. 1, with a slight increase of $5 \%$ from dry to saturated tests $\left(0.22\right.$ to $\left.0.23 \mathrm{MPa} \cdot \mathrm{m}^{0.5}\right)$. In aggregate No. 2 , the water effect reduces the $K_{\mathrm{IC}}$ from average values of 0.21 to $0.14 \mathrm{MPa} \cdot \mathrm{m}^{0.5}$ (i.e., approximately $33 \%$ ) from dry to saturated specimens.
Fig. 5. Stress relaxation during flooding in test F5.

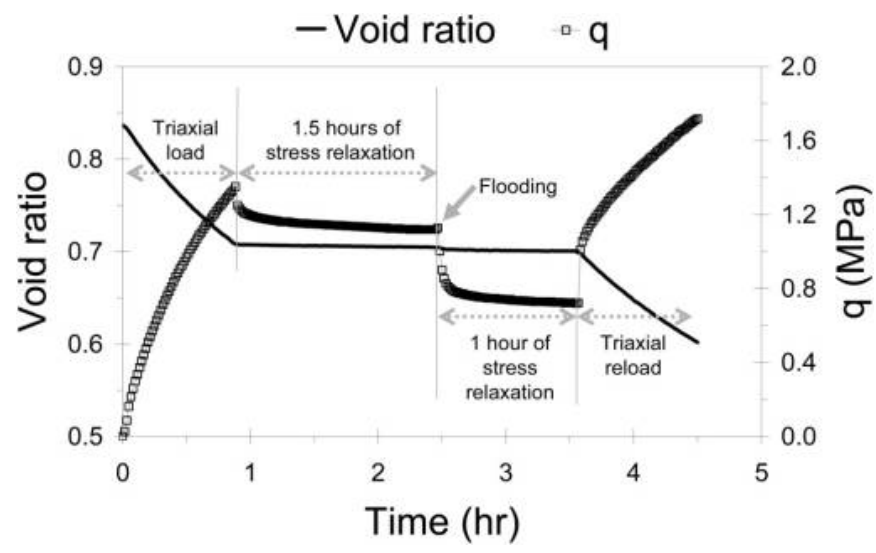

\section{Discussion}

The experimental data presented in this paper show that saturated and flooded crushable granular material samples are more compressible than dry samples, mainly due to the increase of grain crushing in the presence of water. The phenomenon assumes that, for samples prepared with air dried grains, suction in capillary bonds of intergranular contacts is negligible, which is normally the case in rather coarse materials. To validate this hypothesis, an oedometric compression test on a stronger material (where no crushing is expected) was carried out. An air dried sample (19 $\mathrm{mm}$ high and $70 \mathrm{~mm}$ in diameter) of $2 \mathrm{~mm}$ uniformly sized glass beads was compressed, as shown in Fig. 18. After flooding at $\sigma_{\mathrm{v}}^{\prime}=2.1 \mathrm{MPa}$, the plastic strain was negligible and no crushing was observed after the test. Therefore, regarding the results on crushable granular materials presented in this paper, it can be reasonably assumed that flooding triggers particle crushing. According to previous works aforementioned and also regarding our results for the effect of water on $K_{\mathrm{IC}}$, this phenomenon could be explained by a drop in capillary suction at the microcracks scale inside the particles, as well as corrosive attacks of water, reducing their crushing strength.

Numerical analyses by the discrete element method have shown that the stresses applied on an assembly of grains are divided into a limited number of strong force chains in the same principal direction as the macromechanical stresses, as well as several weak force chains stabilizing the system (Cundall and Strack 1979; Voivret et al. 2009). As for the phenomenon of particle crushing, when the coordination number is low (e.g., in uniform graded samples as the material used in this study), it is reasonable to consider that a particle belonging to a strong chain is likely to be crushed in mode I, like in a CCNBD test for $K_{\mathrm{IC}}$ evaluation. However, for well-graded materials the stress conditions could be quite different and, due to the heterogeneity of the sample, microtensile stress fields can be generated within the particles to initiate the grain fracture and fragmentation.

Nevertheless, the effect of saturation on particle crushing and on the compressibility could be more or less significant depending on the material properties and its sensitivity to the presence of water. For instance, Coop and Lee (1995) investigated differences between the amounts of breakage in dry and saturated (flooded) sands and, while they found substantial differences for a decomposed granite and also for a carbonate sand, they did not find substantial differences for a quartz sand.

Our results show that, for given initial conditions (GSD and density) and compression state (stress path and $p_{\max }^{\prime}$ ), the compression curve in the $e-p^{\prime}$ plane of flooded and saturated samples is virtually the same, regardless of the loading-flooding sequence. Hence, after flooding in creep tests we have observed a collapse from the dry to the saturated material compression curve. Likewise, when we 
Fig. 6. Stress-strain curves after triaxial tests.

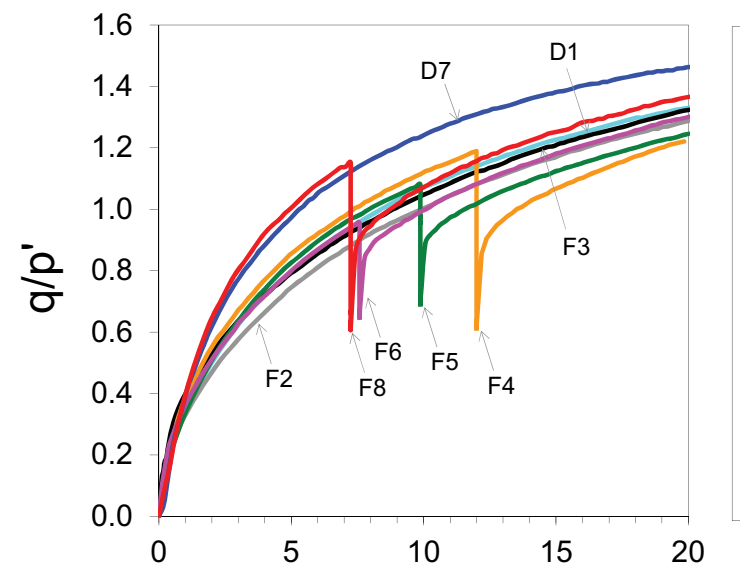

$$
\begin{aligned}
& -\mathrm{D} 1 \\
& -\mathrm{F} 2 \\
& -\mathrm{F} 3 \\
& -\mathrm{F} 4 \\
& -\mathrm{F} 5 \\
& -\mathrm{F} 6 \\
& -\mathrm{D} 7 \\
& -\mathrm{F} 8
\end{aligned}
$$
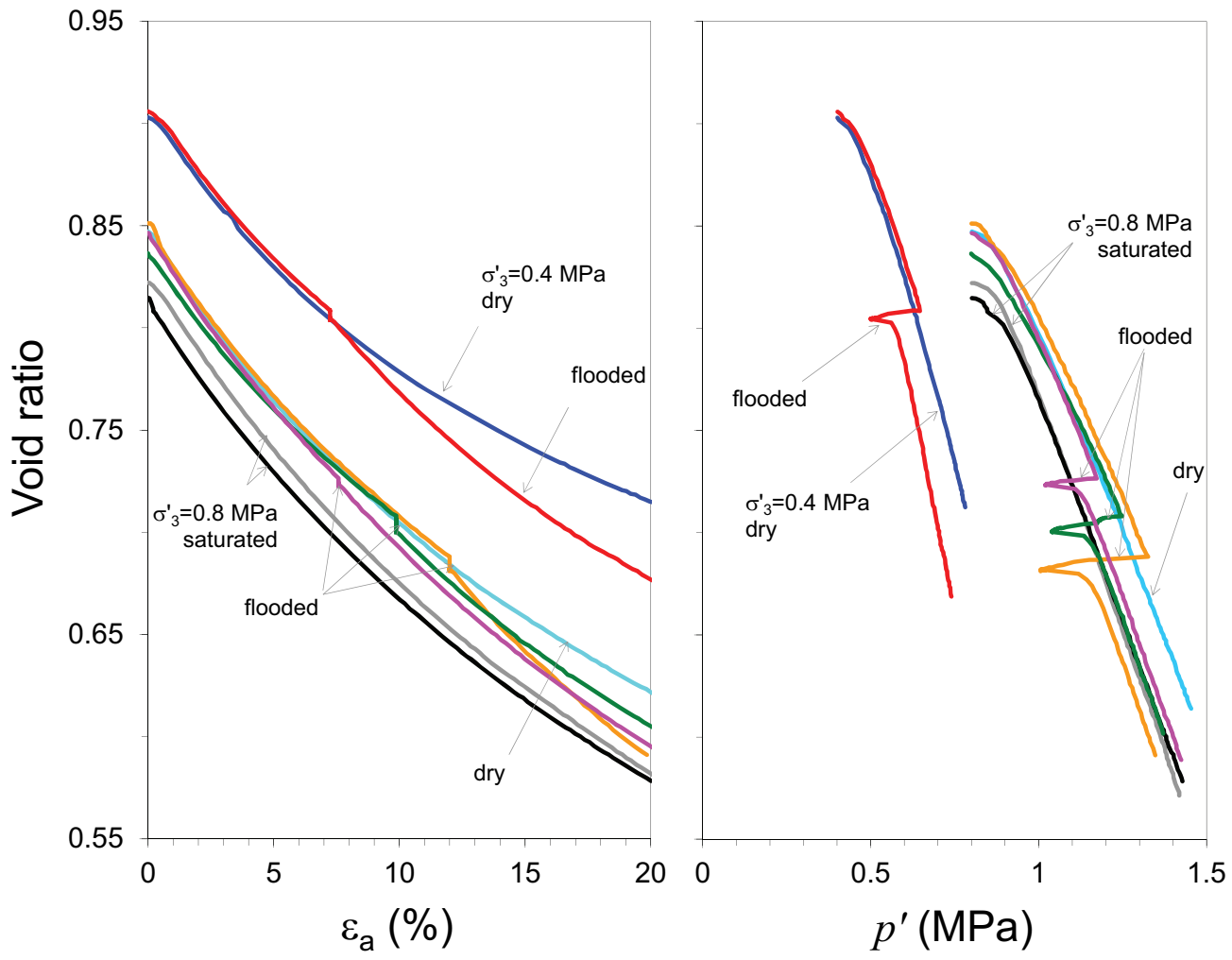

Fig. 7. Compression curves for oedometric tests.

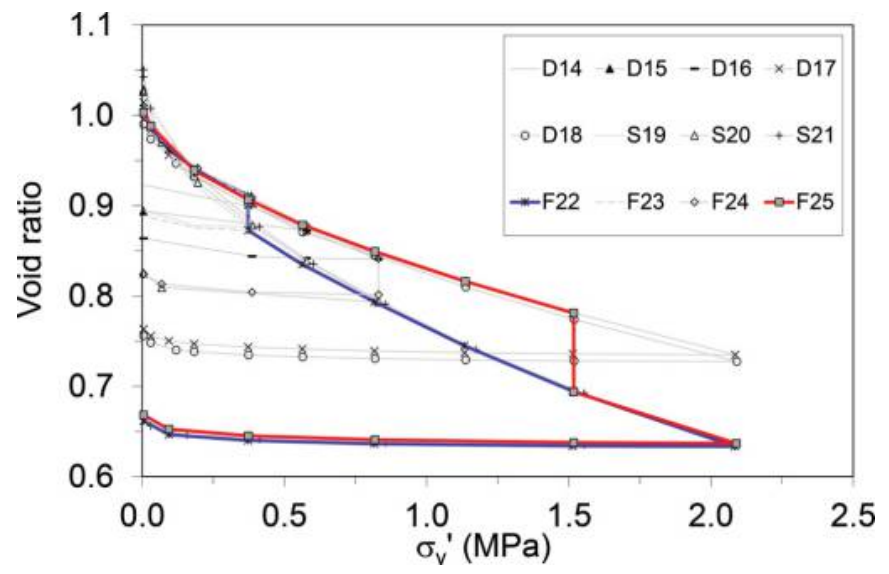

Fig. 8. Grain-size distribution before and after oedometric tests $(1 \mathrm{~h}$ of creep) at $\sigma_{\mathrm{v} \text { max }}^{\prime}=2.1 \mathrm{MPa}$ for dry (D18), saturated (S21), and flooded (F25) samples.

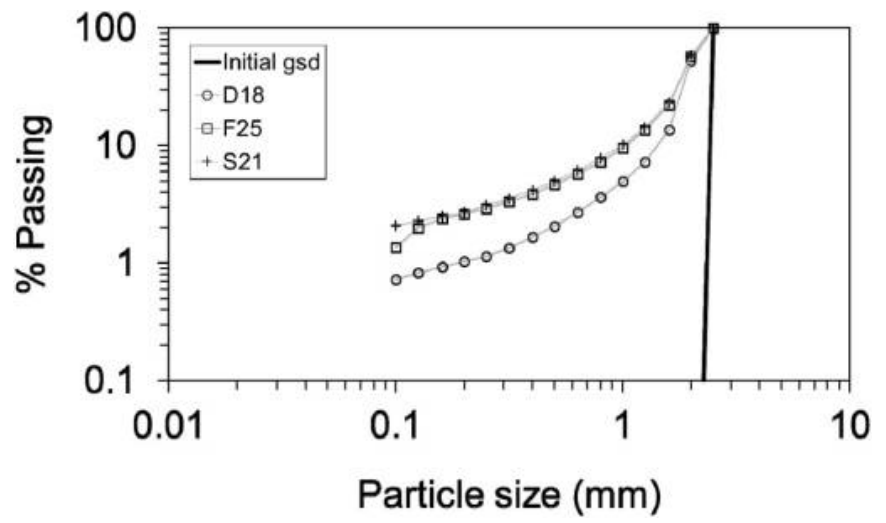


Table 2. Summary of creep tests under oedometric compression.

\begin{tabular}{llllllll}
\hline Test & Initial & & & & & \\
No. & void ratio & $\sigma_{\mathrm{v} \text { max }}^{\prime}(\mathrm{MPa})$ & $B_{\mathrm{r}}(\%)$ & $W^{\mathrm{p}}(\mathrm{MPa})$ & $W^{\mathrm{E}} / W^{\mathrm{T}}(\%)$ & $C_{\mathrm{s}}$ & Test conditions \\
\hline D26 & 0.998 & 0.15 & 2 & 0.003 & 0.9 & 0.004 & Dry \\
D27 & 1.010 & 0.40 & 6 & 0.014 & 0.3 & 0.005 & Dry \\
D28 & 1.034 & 0.80 & 8 & 0.037 & 1.1 & 0.004 & Dry \\
D29 & 1.065 & 0.80 & 9 & 0.043 & 1.2 & 0.005 & Dry \\
D30 & 1.014 & 1.30 & 10 & 0.076 & 1.2 & 0.006 & Dry \\
D31 & 1.011 & 1.30 & 11 & 0.077 & 1.1 & 0.005 & Dry \\
D32 & 1.037 & 2.10 & 12 & 0.000 & 0.1 & 0.006 & Dry \\
D33 & 1.010 & 2.10 & 13 & 0.129 & 1.3 & - & Dry \\
S34 & 0.994 & 0.15 & 3 & 0.005 & 0.7 & 0.004 & Saturated \\
S35 & 1.005 & 0.40 & 7 & 0.017 & 0.3 & 0.005 & Saturated \\
S36 & 1.010 & 0.40 & 8 & 0.018 & 0.2 & 0.004 & Saturated \\
S37 & 1.026 & 0.80 & 11 & 0.000 & 0.1 & 0.006 & Saturated \\
S38 & 1.016 & 1.30 & 12 & 0.000 & 1.4 & 0.006 & Saturated \\
S39 & 1.020 & 1.30 & 13 & 0.105 & 1.5 & 0.006 & Saturated \\
S40 & 0.994 & 2.10 & 20 & 0.191 & 0.9 & 0.006 & Saturated \\
S41 & 0.995 & 2.10 & 20 & 0.189 & 0.0 & 0.006 & Saturated \\
F42 & 1.010 & 0.15 & - & 0.006 & 0.6 & 0.005 & Flooded at $\sigma_{v}^{\prime}=0.15 \mathrm{MPa}$ \\
F43 & 1.007 & 0.40 & 8 & 0.021 & 0.2 & 0.005 & Flooded at $\sigma_{\mathrm{v}}^{\prime}=0.40 \mathrm{MPa}$ \\
F44 & 1.036 & 0.80 & 12 & 0.064 & 0.7 & 0.005 & Flooded at $\sigma_{\mathrm{v}}^{\prime}=0.80 \mathrm{MPa}$ \\
F45 & 1.006 & 1.30 & 14 & 0.118 & 0.9 & 0.006 & Flooded at $\sigma_{\mathrm{v}}^{\prime}=1.30 \mathrm{MPa}$ \\
F46 & 1.045 & 2.10 & 21 & 0.286 & 0.0 & 0.007 & Flooded at $\sigma_{\mathrm{v}}^{\prime}=2.10 \mathrm{MPa}$ \\
F47 & 1.062 & 2.10 & 17 & 0.257 & 1.1 & 0.006 & Flooded at $\sigma_{\mathrm{v}}^{\prime}=2.10 \mathrm{MPa}$ \\
F48 & 1.029 & 2.10 & 8 & 0.248 & 1.2 & 0.007 & Flooded at $\sigma_{\mathrm{v}}^{\prime}=2.10 \mathrm{MPa}$ \\
F49 & 0.920 & 2.10 & 20 & 0.216 & 1.9 & 0.006 & Flooded at $\sigma_{\mathrm{v}}^{\prime}=2.10 \mathrm{MPa}$ \\
S50 & 0.906 & 2.10 & 18 & 0.163 & 1.4 & 0.007 & Saturated \\
D51 & 0.934 & 2.10 & 13 & 0.123 & 1.4 & 0.006 & Dry \\
\hline
\end{tabular}

Note: $C_{\mathrm{s}}$, unloading stiffness $\left(=\Delta \varepsilon_{\mathrm{v}} / \log \left(\sigma_{\mathrm{v} \text { max }}^{\prime} / \sigma_{\mathrm{v} \text { min }}^{\prime}\right)\right) ; W^{\mathrm{E}}$, elastic work; $W^{\mathrm{T}}$, total work.

Fig. 9. Oedometric compression curves for $24 \mathrm{~h}$ of creep.

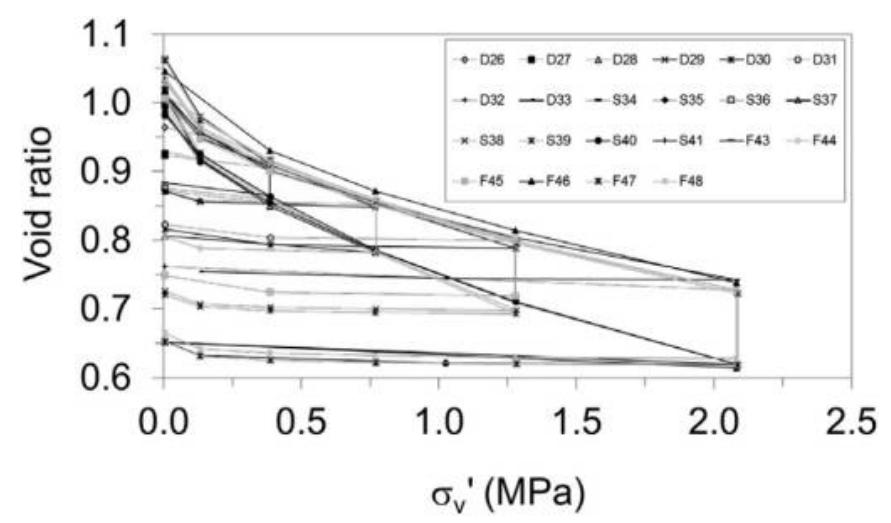

Fig. 10. Grain-size distribution before and after oedometric tests (24 h of creep) at $\sigma_{\mathrm{v} \text { max }}^{\prime}=2.1 \mathrm{MPa}$ for dry (D32), saturated (S40), and flooded (F47) samples.

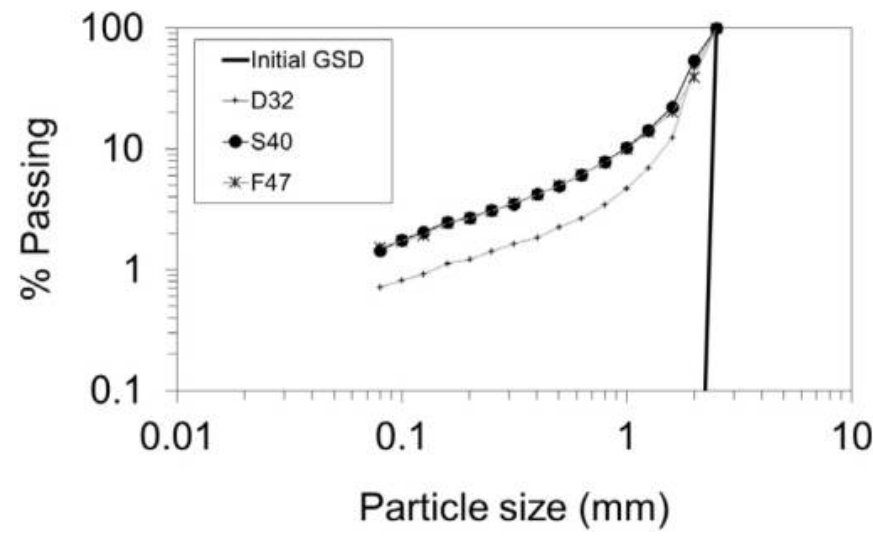

Fig. 11. Compression curves for selected oedometric tests on log-scale.

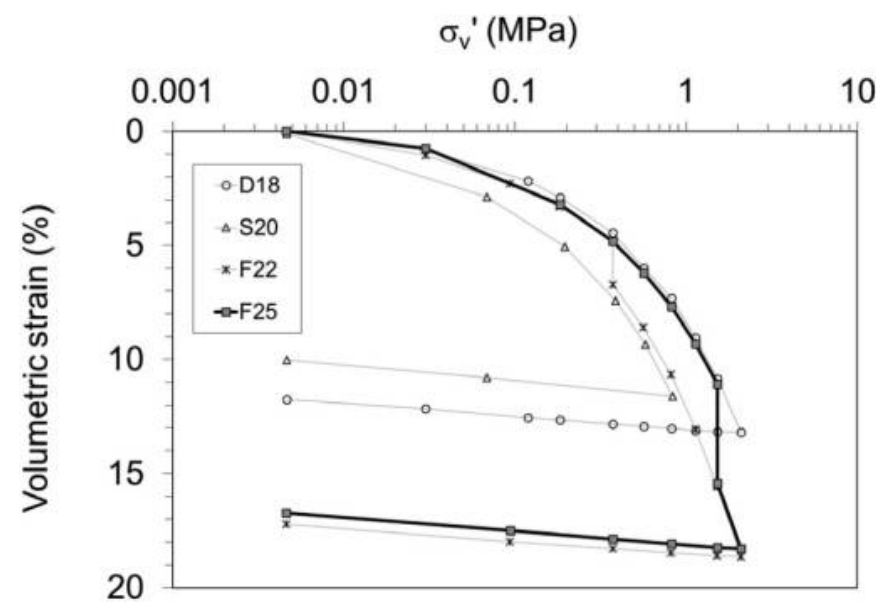

reloaded a sample previously flooded during a stress relaxation phase, the compression curves did not return to the earlier dry material response, but rather followed the one of the saturated material. As shown experimentally by Biarez and Hicher (1997) and numerically by Voivret et al. (2007), the void ratio attained at a given stress state is linked to the GSD: the more polydisperse the GSD is, the higher the packing density will be. Therefore, the uniqueness of the compression curve of saturated and flooded sand tests can be explained because they have reached the same GSD, which was made possible due to grain crushing.

Moreover, the uniqueness of the mechanical response for flooded and saturated samples for a given stress path is also observed in the behavior under creep. The creep compressibility index increases with the mean stress, and, for a given stress, its magnitude is higher for saturated samples compared to dry ones. After flooding, this index increases to the same value obtained in 
Fig. 12. Breakage ratio after oedometric tests ( $1 \mathrm{~h}$ and $24 \mathrm{~h}$ of creep) for dry and saturated samples.

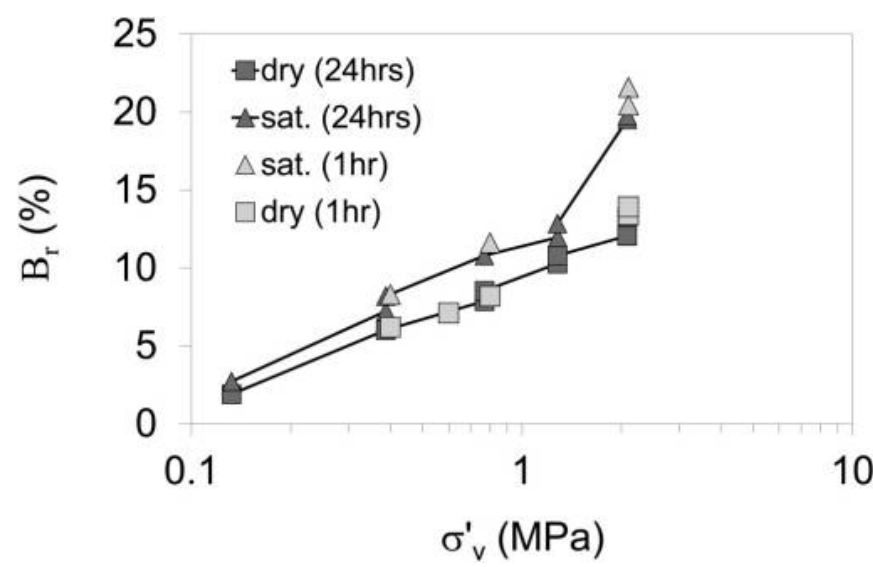

Fig. 13. $24 \%$ of creep during oedometric compression.

(a) test D32

Time $(\min )$

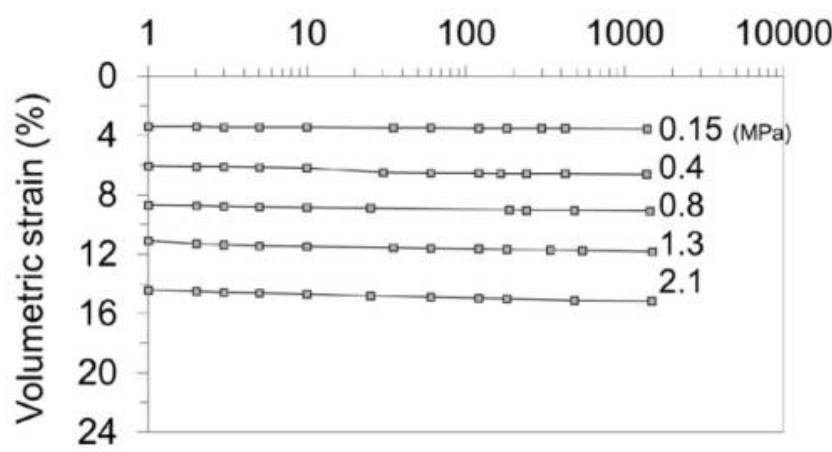

(b) test $\mathrm{S41}$

Time (min)

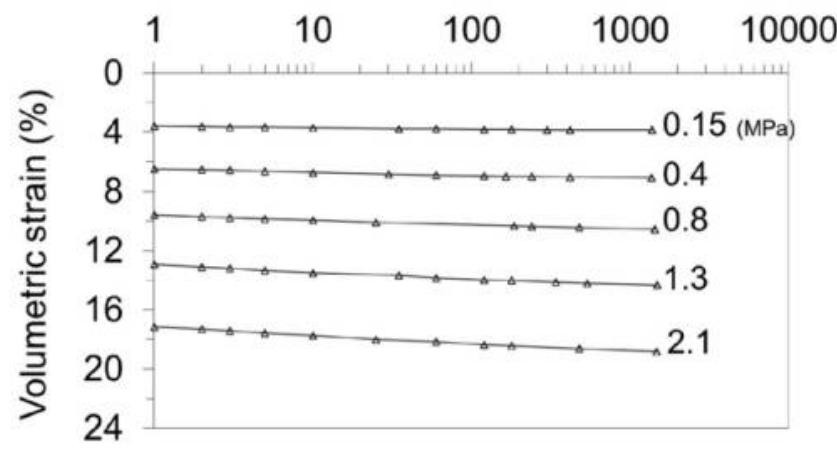

(c) test F46

Time (min)

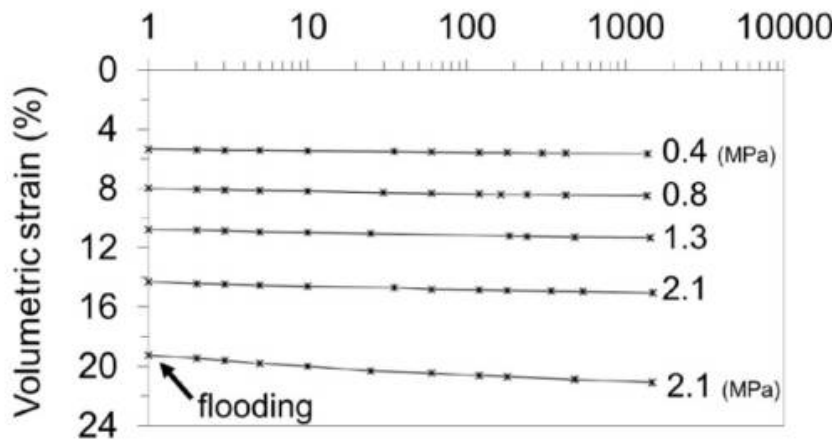

Fig. 14. Creep compressibility index.
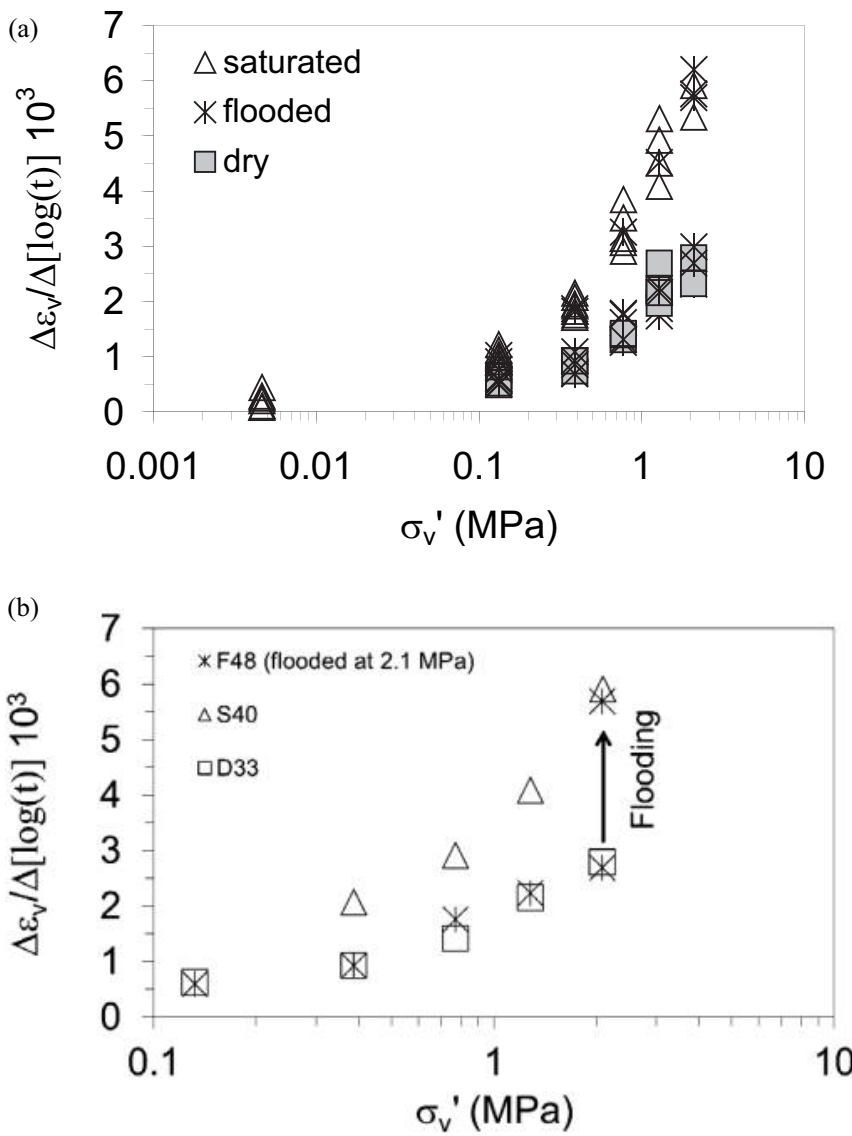

Fig. 15. CCNBD specimen geometry with recommended test fixture (reprinted from Fowell 1995, with permission from Elsevier).

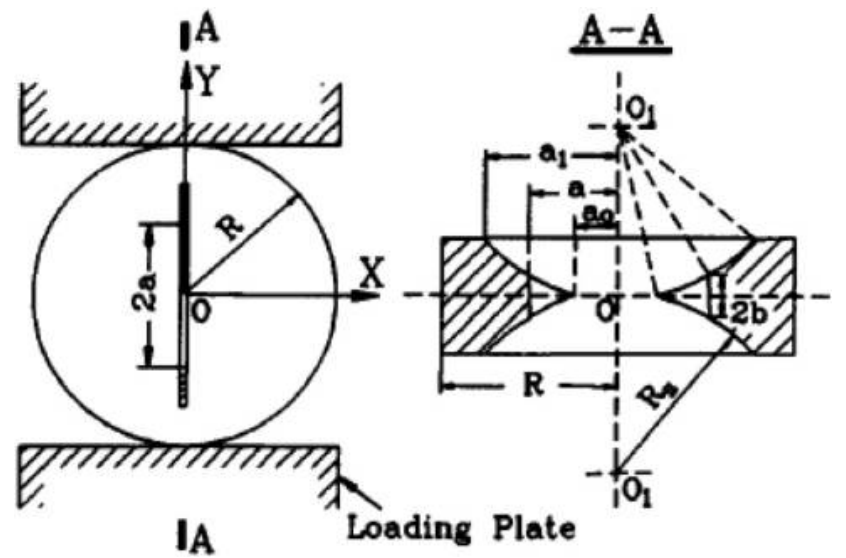

saturated samples, analogous to the results on both the compression curve and the breakage ratio. As reported in the literature, this could be explained due to the increment of crack propagation velocity inside the grains in the presence of water (Oldecop and Alonso 2007).

To study the effect of the initial density, three denser samples were prepared by vibration and compressed at an average initial void ratio of 0.920 , using the same previous methodology for $24 \mathrm{~h}$ creep oedometer tests (see tests F49 to D51 in Table 2). Figure 18 presents the compression curves for dense samples and also a summary of the most representative compression curves for loose ones. It can be seen that all dry, saturated, and flooded dense samples follow lower compression curves in comparison to loose 
Fig. 16. Core rock samples for two directions: orthogonal and parallel; machined from rock aggregate No. 2 .

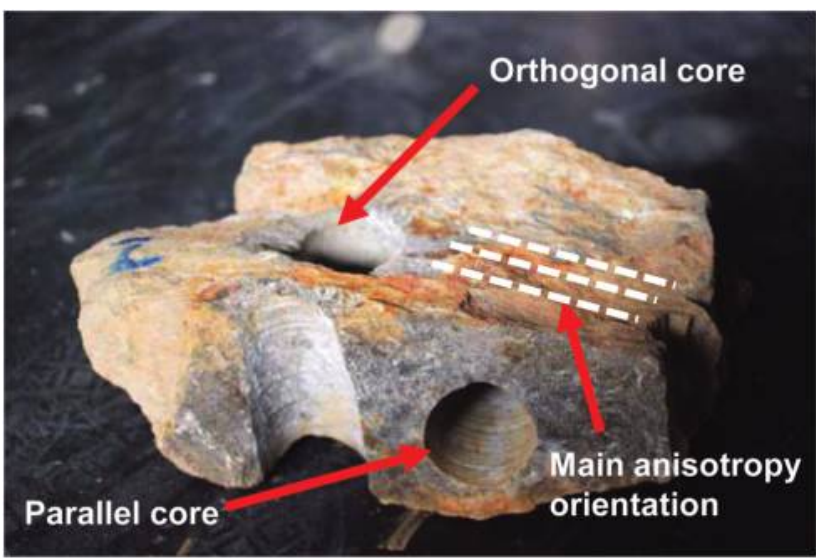

Fig. 17. Measurement of compression force and vertical displacements of the CCNBD sample.

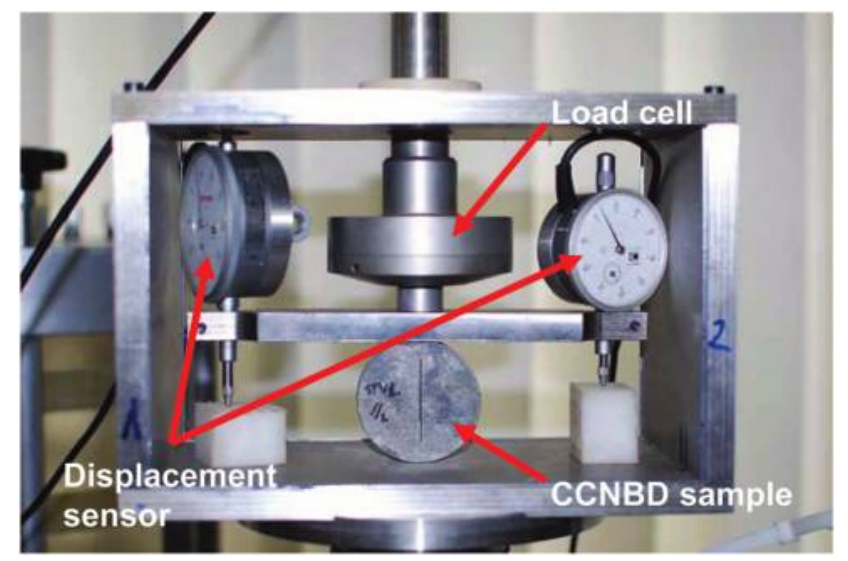

Table 3. Mode I fracture toughness of CCNBD specimens with orthogonal core orientation.

\begin{tabular}{llll}
\hline Rock aggregate & Sample No. & Condition & $K_{\mathrm{IC}}\left(\mathrm{MPa} \cdot \mathrm{m}^{0.5}\right)$ \\
\hline 1 & 1 & Saturated & 0.58 \\
& 2 & Saturated & 0.59 \\
& 3 & Dry & 1.48 \\
& 4 & Dry & 1.57 \\
2 & 5 & Dry & 1.49 \\
& 1 & Saturated & 0.42 \\
& 2 & Dry & 0.54 \\
& 3 & Dry & 0.63 \\
\hline
\end{tabular}

Table 4. Mode I fracture toughness of CCNBD specimens with parallel core orientation.

\begin{tabular}{llll}
\hline Rock aggregate & Sample No. & Condition & $K_{\mathrm{IC}}\left(\mathrm{MPa} \cdot \mathrm{m}^{0.5}\right)$ \\
\hline 1 & 1 & Saturated & 0.23 \\
2 & 2 & Dry & 0.22 \\
& 1 & Saturated & 0.16 \\
& 2 & Saturated & 0.11 \\
& 3 & Dry & 0.21 \\
& 4 & Dry & 0.22 \\
& 5 & Dry & 0.19 \\
& 6 & Dry & 0.23 \\
\hline
\end{tabular}

Fig. 18. Oedometric compression curves for loose and dense samples.

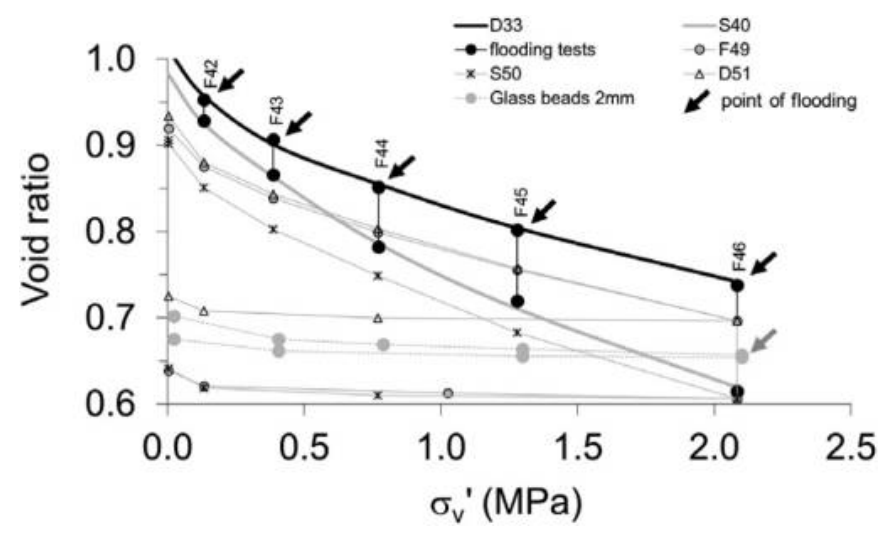

ones. However, dense and loose samples tend to produce a unique response at high stresses (not completely reached at $\sigma_{\mathrm{v}}^{\prime}=2.1 \mathrm{MPa}$ ). This is clearer for saturated and flooded samples, where the void ratio at $\sigma_{\mathrm{v}}^{\prime}=2.1 \mathrm{MPa}$ is slightly lower than the one for loose samples. For every test loaded at $\sigma_{\mathrm{v} \text { max }}^{\prime}=2.1 \mathrm{MPa}$ (from Table 2), the final GSD is shown in Fig. 19. It can be seen that the GSDs after the tests for saturated and flooded samples are almost the same for both loose and dense cases. However, the dry dense sample (test D51) presents clearly more crushing than do the dry loose samples (tests D32 and D33), which is in agreement with the denser state reached at $\sigma_{\mathrm{v}}^{\prime}=2.1 \mathrm{MPa}$ in Fig. 18 .

Figure 20 presents $B_{\mathrm{r}}$ as a function of the plastic work $\left(W^{\mathrm{p}}\right)$ for all loose samples (tests D1 to F48). In the calculation of the plastic dissipation, we have assumed all the unloading strains to be elastic. Therefore, $W^{\mathrm{p}}$ in a test was estimated as the sum of all increments of the total work $\left(W^{\mathrm{T}}\right)$ done in compression $\Delta W=p^{\prime}\left(\Delta \varepsilon_{\mathrm{v}}\right)+$ $q\left(\Delta \varepsilon_{s}\right)$ (loading), minus the recovered elastic strain during unloading (where $\Delta \varepsilon_{\mathrm{v}}$ and $\Delta \varepsilon_{\mathrm{s}}$ are the volumetric and the deviatoric strain increments, respectively). For instance, in oedometric tests the unloading stiffness, computed as $C_{\mathrm{s}}=\Delta \varepsilon_{\mathrm{v}} / \log \left(\sigma_{\mathrm{v} \text { max }}^{\prime} / \sigma_{\mathrm{v} \text { min }}^{\prime}\right)$, varies between 0.004 at low stresses and 0.007 at high stresses, as shown in Table 2 and in Fig. 21 (for tests D26 to F48). On the other hand, in dry samples $C_{\mathrm{s}}$ resulted in slightly lower values for dry samples compared with saturated and flooded ones. Finally, the elastic strain recovery has resulted to be negligible compared with the accumulated plastic strain. For instance, Table 2 shows that the elastic work, obtained as $W^{\mathrm{E}}=W^{\mathrm{T}}-W^{\mathrm{P}}$, is less than $2 \%$ of $W^{\mathrm{T}}$.

According to Fig. 20, dry materials (squares symbols) require more $W^{\mathrm{P}}$ to reach a given $B_{\mathrm{r}}$, compared to saturated and flooded cases, which can be considered as equivalent. This result does not depend on the stress path and could be explained because, unlike in dry condition, wet grains have lower particle strength due to the reduction of the fracture toughness when the water content increases. Therefore, more energy dissipation is needed in a dry sample to reach a given GSD, compared with saturated or flooded samples. Consequently, for a material with a given initial density and initial GSD, the amount of particle breakage depends only on the plastic work and on the water content. At the same time, the plastic dissipation in crushable materials has different sources. It has been proposed that, once a breakage event occurs, the elastic energy stored within the grain is converted in fracture surface energy and in kinetic energy in fragments and also in surrounding grains, due to pore collapse and fragments rearrangement (Nguyen and Einav 2009; Russell 2011). Then, the system will reach a new static equilibrium state, where the kinetic energy will be divided into some recovered elastic energy and dissipation by friction at newly formed contacts. Finally, the internal energy distribution plays a major role compared to surface area creation (Ovalle et al. 2013a; Russell and Einav 2013). The relation presented in Fig. 20 does not make the difference of those contributions and 
Fig. 19. Grain-size distribution before and after oedometric tests of loose and dense samples at $\sigma_{\mathrm{v} \text { max }}^{\prime}=2.1 \mathrm{MPa}$.

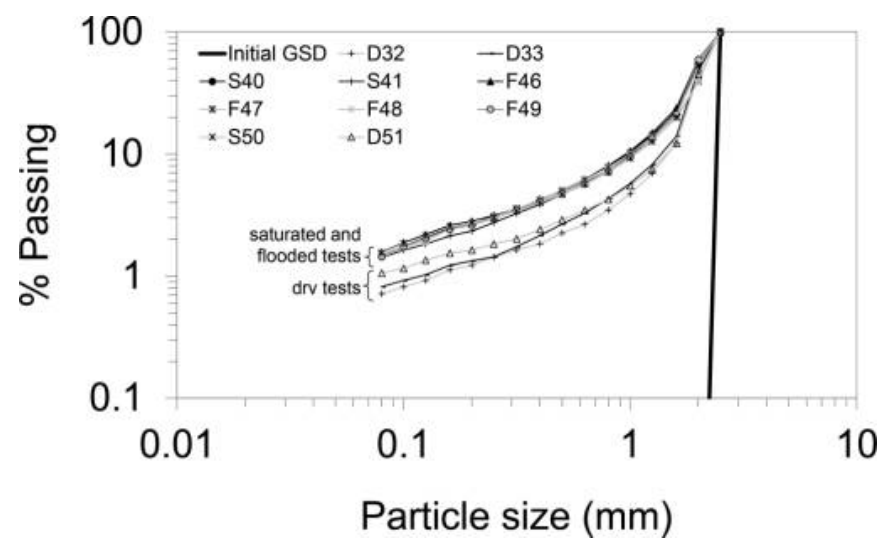

Fig. 20. Breakage ratio versus plastic work for all tests.

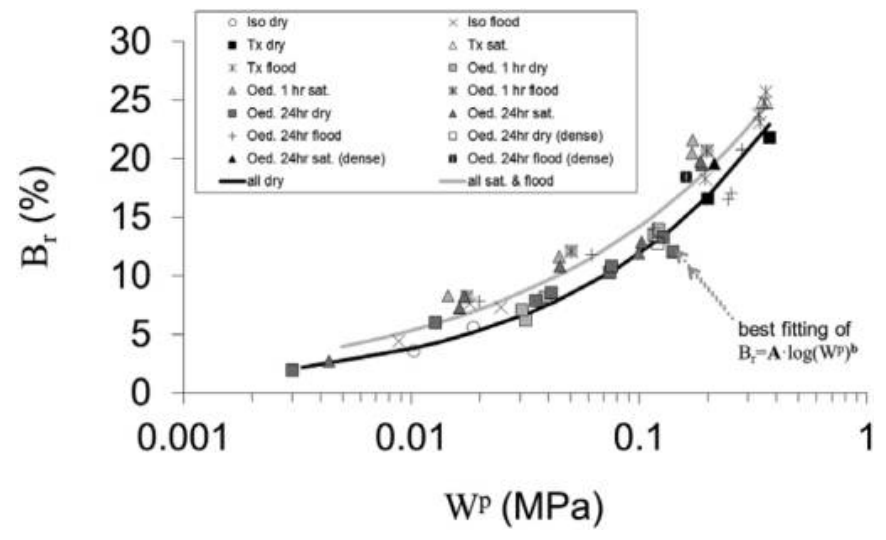

Fig. 21. Unloading stiffness $C_{\mathrm{s}}$ in oedometric tests.

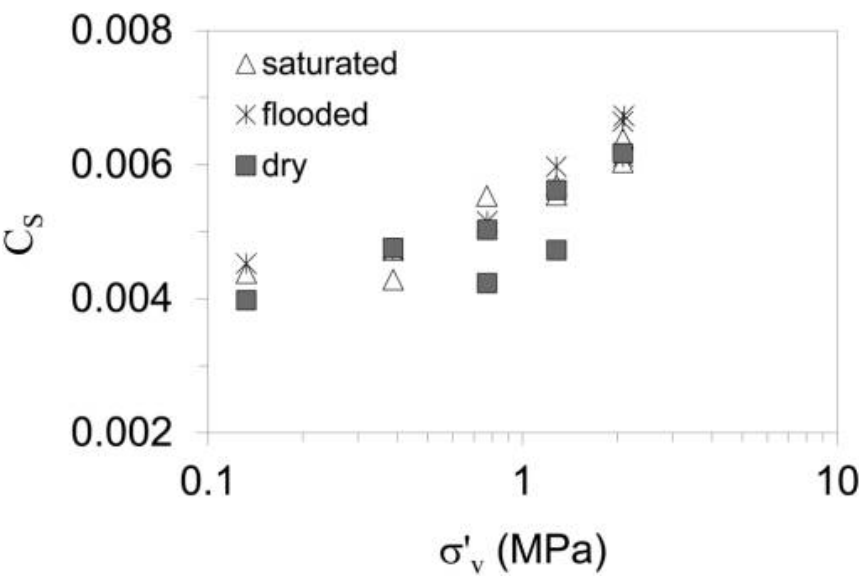

simply suggests that there is coupling between breakage dissipation and plastic dissipation, since both phenomena evolve simultaneously.

Figure 22 presents the relation between $B_{\mathrm{r}}$ and the lowest void ratio attained for each test presented here (tests D1 to D51). For the material used here, this relation can be regarded as unique and does not depend on the loading condition (stress path, creep, or relaxation) or on the test particular condition (dry, saturated or flooded). However, it should depend on the initial density and on intrinsic parameters such as the particle shape and the initial GSD. This finding means that, irrespective of the stress path and the water content, the granular packing at static equilibrium only depends on its GSD.
Fig. 22. Breakage ratio versus the minimal void ratio for all tests.

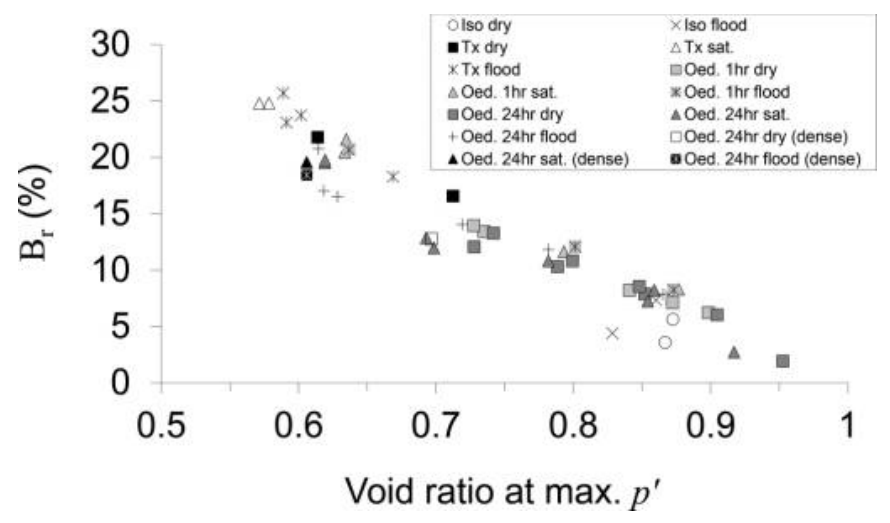

Analogically, Biarez and Hicher (1997) have shown that, for a given grain shape, reference void ratios $e_{\max }$ and $e_{\min }$ are linked with the uniformity coefficient. Moreover, they stated that, to highlight the influence of grain crushing, it appears that the most significant parameter, for a given mineralogy and grain shape, is the GSD, with noticeable effects on the volume change amplitudes during compression. This evidence can be useful for constitutive modeling, since the prediction of the final GSD could be based on calibration tests along only one given stress path. Moreover, constitutive models based on a critical void ratio function of the amount of grain crushing, as in the pioneering work of Daouadji et al. (2001), could be enhanced to model the effect of water on grain crushing. Nevertheless, only three dense samples were tested in this study. Therefore, more results are needed to assess the effect of the initial packing on this material. For instance, Altuhafi and Coop (2010) have shown that the denser the initial packing is, the less amount of breakage will result (for silica sand, carbonate sand, and basaltic sand tested in oedometric compression up to $\sigma_{\mathrm{v}}^{\prime}=30 \mathrm{MPa}$ ). On the other hand, the experimental assessment of initial density effects is a complex problem because during dense sample preparation some crushing eventually occurs. Therefore, both grading and density effects could be mixed.

The results provided in this paper concern stress magnitudes that could be of interest in civil engineering. However, for high stresses and (or) large strains, grading evolves to an ultimate distribution that might be defined by a given uniformity coefficient (Bard 1993; Biarez and Hicher 1994, 1997) or by a fractal exponent of approximately $D=2.5$ (Sammis et al. 1986; Coop et al. 2004). Therefore, the results shown in Figs. 20 and 22 should not be extrapolated to outlying range values.

\section{Conclusions}

With the aim to explore and discuss the effect of water on the mechanical behavior of crushable granular materials, we have presented the results of a series of compression tests under isotropic, oedometric, and triaxial stress paths. We have compared the data of dry, saturated, and flooded samples, to establish an empirical framework based on the breakage ratio. Our results show that the amount of particle crushing increases in the presence of water and, as a consequence, the material becomes more compressible. Furthermore, for a given initial density and stress path, a dry sample when flooded reaches the equivalent behavior of an initially saturated one in terms of the compression curve, the breakage ratio and the creep compressibility index, regardless of the point of flooding. We have also found a unique relation between the breakage ratio and the lowest void ratio in a compression test at a given initial density, regardless of the stress path, the water content, the point of flooding, nor the time of creep or stress relaxation.

These findings could enhance future constitutive models based on grading to predict the influence of the water content on parti- 
cle breakage and time effects. This work could also be used for further study on water and time effects on the micromechanics of granular media and a better understanding of the corrosive attack of water in microcracks as a coupled phenomenon of $(i)$ a decrease of $K_{\mathrm{IC}}$ and (ii) an increase of crack propagation velocity could be attained. The focus could be the effect of the rock mineralogy, the chemical composition of the water, and other factors of influence. Moreover, it would be interesting to have a general framework based on measurements of the humidity retained into solid grains. Such results could be a base for physical-based models depending on suction in microcracks.

\section{Acknowledgements}

The authors express their appreciation for the scientific collaboration with Erich Bauer from Graz University of Technology. His useful comments and encouragement to publish our results have contributed to the writing of this article. Carlos Ovalle gratefully acknowledges CONICYT Chile, the Embassy of France in Chile, and the financial support of the Vicerrectoría de Investigación VRI, Pontificia Universidad Católica de Chile, through projects PIA 2014 3519-301 and INICIO 7/2014.

\section{References}

Altuhafi, F.N., and Coop, M.R. 2010. Changes to particle characteristics associated with the compression of sands. Géotechnique, 61(6): 459-471. doi:10. 1680/geot.9.P.114.

Ashby, M., and Jones, D. 2006. Engineering materials 1. 3rd ed. Elsevier, Oxford.

Atkinson, B.K. 1979. A fracture mechanics study of subcritical tensile cracking of quartz in wet environments. Pure and Applied Geophysics, 117: 1011-1024. doi:10.1007/BF00876082.

Atkinson, B.K. 1982. Subcritical crack propagation in rocks: theory, experimental results and applications. Journal of Structural Geology, 4(1): 41-56. doi:10. 1016/0191-8141(82)90005-0.

Bard, E. 1993. Comportement des matériaux granulaires secs et à liant hydrocarboné. Doctoral thesis, Ecole Centrale de Paris, France.

Bauer, E. 2009. Hypoplastic modelling of moisture-sensitive weathered rockfill materials. Acta Geotechnica, 4: 261-272. doi:10.1007/s11440-009-0099-y.

Biarez, J., and Hicher, P.Y. 1994. Elementary mechanics of soil behaviour. Balkema, Rotterdam.

Biarez, J., and Hicher, P.Y. 1997. Influence de la granulométrie et de son évolution par ruptures de grains sur le comportement mécanique de matériaux granulaires. Revue Française de Génie Civil, 1(4): 607-631.

Buscarnera, G., and Einav, I. 2012. The yielding of brittle unsaturated granular soils. Géotechnique, 62(2): 147-160. doi:10.1680/geot.10.P.118.

Chávez, C., and Alonso, E.E. 2003. A constitutive model for crushed granular aggregates which includes suction effects. Soils and Foundations, 43(4): 215227. doi:10.3208/sandf.43.4_215.

Coop, M.R., and Lee, I.K. 1995. The influence of pore water on the mechanics of granular soils. In Proceedings of the XI European Conference on Soil Mechanics and Foundation Engineering, Copenhagen, Danish Geotechnical Society. pp. 1.63-1.72.

Coop, M.R., Sorensen, K.K., Bodas Freitas, T., and Georgoutsos, G. 2004. Particle breakage during shearing of a carbonate sand. Géotechnique, 54(3): 157-163. doi:10.1680/geot.2004.54.3.157.

Cundall, P., and Strack, O. 1979. A discrete numerical model for granular assemblies. Géotechnique, 29(1): 47-65. doi:10.1680/geot.1979.29.1.47.

Daouadji, A., and Hicher, P.-Y. 2010. An enhanced constitutive model for crushable granular materials. International Journal for Numerical and Analytical Methods in Geomechanics, 34(6): 555-580. doi:10.1002/nag.815.

Daouadji, A., Hicher, P.-Y., and Rahma, A. 2001. An elastoplastic model for granular materials taking into account grain breakage. European Journal of Mechanics A Solids, 20: 113-137. doi:10.1016/S0997-7538(00)01130-X.

Dunning, J.D., Petrovski, D., Schuyler, J., and Owens, A. 1984. The effects of aqueous chemical environments on crack propagation in quartz. Journal of Geophysical Research, 89(B6): 4115-4123. doi:10.1029/JB089iB06p04115.

Einav, I. 2007a. Breakage mechanics. Part I: Theory. Journal of the Mechanics and Physics of Solids, 55(6): 1274-1297. doi:10.1016/j.jmps.2006.11.003.

Einav, I. 2007b. Breakage mechanics. Part II: Modelling granular materials. Journal of the Mechanics and Physics of Solids, 55(6): 1298-1320. doi:10.1016/j. jmps.2006.11.004.

Fowell, R.J. 1995. Suggested method for determining mode I fracture toughness using Cracked Chevron Notched Brazilian disc (CCNBD) specimens. International Journal of Rock Mechanics and Mining Sciences \& Geomechanics Abstracts, 32(1): 57-64. doi:10.1016/0148-9062(94)00015-U.

Frossard, E., Hu, W., Dano, C., and Hicher, P.-Y. 2012. Rockfill shear strength evaluation: a rational method based on size effects. Géotechnique, 62(5): 415-428. doi:10.1680/geot.10.P.079.

Griffith, A.A. 1921. The phenomena of rupture and flow in solids. Philosophical
Transactions of the Royal Society A: Mathematical, Physical and Engineering Sciences, 221: 163-198. doi:10.1098/rsta.1921.0006.

Hardin, B.O. 1985. Crushing of soil particles. Journal of Geotechnical Engineering, 111(10): 1177-1192. doi:10.1061/(ASCE)0733-9410(1985)111:10(1177).

Hu, W., Yin, Z., Dano, C., and Hicher, P.-Y. 2011. A constitutive model for granular materials considering grain breakage. Science China Technological Sciences, 54: 2188-2196. doi:10.1007/s11431-011-4491-0.

Irwin, G. 1957. Analysis of stresses and strains near the end of a crack traversing a plate. Journal of Applied Mechanics, 24: 361-364.

Lade, P.V., Yamamuro, J.A., and Bopp, P.A. 1996. Significance of particle crushing in granular materials. Journal of Geotechnical Engineering, 122(4): 309-316. doi:10.1061/(ASCE)0733-9410(1996)122:4(309).

Lee, I.K., and Coop, M.R. 1995. The intrinsic behaviour of a decomposed granite soil. Géotechnique, 45(1): 117-130. doi:10.1680/geot.1995.45.1.117.

Li, G., Ovalle, C., Dano, C., and Hicher, P.-Y. 2013. Influence of grain size distribution on critical states of granular materials. In Constitutive modeling of geomaterials. Edited by Q. Yang, J.-M. Zhang, H. Zheng, and Y. Yao. Springer Series in Geomechanics and Geoengineering. Springer, Berlin. pp. 207-210. doi:10.1007/978-3-642-32814-5_25.

Marachi, N.D., Chan, C.K., and Seed, H.B. 1972. Evaluation of properties of rockfill materials. Journal of the Soil Mechanics and Foundation Division, ASCE, 98(1): 95-114.

Marsal, R. 1973. Mechanical properties of rockfill dams. In Embankment-dam engineering: Casagrande Volume. Edited by R.C. Hirschfeld and S.J. Poulos. Wiley, New York, $454 \mathrm{p}$

McDowell, G.R., and Bolton, M.D. 1998. On the micromechanics of crushable aggregates. Géotechnique, 48(5): 667-679. doi:10.1680/geot.1998.48.5.667.

Miura, N., and O-Hara, S. 1979. Particle-crushing of a decomposed granite soil under shear stresses. Soils and Foundations, 19(3): 1-14. doi:10.3208/sandf1972. 19.3_1.

Muir Wood, D., Kikumoto, M., and Russell, A.R. 2009. Particle crushing and deformation behaviour. In Prediction and simulation methods for geohazard mitigation. Edited by F. Oka, A. Murakami, and S. Kimoto. CRC Press, London.

Nguyen., G.D., and Einav, I. 2009. The energetics of cataclasis based on breakage mechanics. Pure and Applied Geophysics, 166: 1693-1724. doi:10.1007/s00024009-0518-X.

Oldecop, L., and Alonso, E. 2001. A model for rockfill compressibility. Géotechnique, 51(2): 127-139. doi:10.1680/geot.2001.51.2.127.

Oldecop, L., and Alonso, E. 2003. Suction effects on rockfill compressibility. Géotechnique, 53(2): 289-292. doi:10.1680/geot.2003.53.2.289.

Oldecop, L., and Alonso, E. 2007. Theoretical investigation of the time dependent behavior of rockfill. Géotechnique, 57(3): 289-301. doi:10.1680/geot.2007.57. 3.289 .

Ovalle, C. 2013. Contribution à l'étude de la rupture des grains dans les matériaux granulaires. Doctoral thesis, Ecole Centrale de Nantes, France. Available at https://tel.archives-ouvertes.fr/tel-00979827 (accessed 16 January 2015).

Ovalle, C., Dano, C., and Hicher, P.-Y. 2013a. Experimental data highlighting the role of surface fracture energy in quasi-static confined comminution. International Journal of Fracture, 182(1): 123-130. doi:10.1007/s10704-013-9833-4.

Ovalle, C., Frossard, E., Dano, C., Hu, W., Maiolino, S., and Hicher, P.-Y. 2013b. The effect of size on the strength of coarse rock aggregates and large rockfill samples through experimental data. Acta Mechanica, 225(8): 2199-2216. doi: 10.1007/s00707-014-1127-z.

Ovalle, C., Voivret, C., Dano, C., and Hicher, P.-Y. 2013c. A probabilistic approach of confined comminution in polydisperse granular materials. Powders and Grains, July 8-12 2013, Sydney, Australia. AIP Conference Proceedings, 1542: 903-906. doi:10.1063/1.4812078.

Russell, A.R. 2011. A compression line for soils with evolving particle and pore size distributions due to particle crushing. Géotechnique Letters, 1: 5-9. doi:10.1680/geolett.10.00003.

Russell, A.R., and Einav, I. 2013. Energy dissipation from particulate systems undergoing a single particle crushing event. Granular Matter, 15(3): 299-314. doi:10.1007/s10035-013-0408-x.

Russell, A.R., and Khalili, N. 2004. A bounding surface plasticity model for sands exhibiting particle crushing. Canadian Geotechnical Journal, 41(6): 11791192. doi:10.1139/t04-065.

Sammis, C.G., Osborne, R.H., Anderson, J.L., Banerdt, M., and White, P. 1986. Self-similar cataclasis in the formation of fault gouge. Pure and Applied Geophysics, 124(1-2): 53-78. doi:10.1007/BF00875719.

Vesic, A.S., and Clough, G.W. 1968. Behaviour of granular materials under high stresses. Journal of the Soil Mechanics and Foundations Division, ASCE, 94(3): 661-688.

Voivret, C., Radjaï, F., Delenne, J.-Y., and El Youssoufi, M.S. 2007. Space-filling properties of polydisperse granular media. Physical Review E, 76: 021301. doi:10.1103/PhysRevE.76.021301.

Voivret, C., Radjaï, F., Delenne, J.-Y., and El Youssoufi, M.S. 2009. Multiscale force networks in highly polydisperse granular media. Physical Review Letters, 102: 178001. doi:10.1103/PhysRevLett.102.178001.

Westwood, A.R.C. 1974. Tewksbury lecture: Control and application of environmentsensitive fracture processes. Journal of Materials Science, 9: 1871-1895. doi:10. 1007/BF00541760.

Whittaker, B.N., Singh, R.N., and Sun, G. 1992. Rock fracture mechanics principles, design and applications. Elsevier, Amsterdam. 